\title{
A high-repetition rate scheme for synchrotron-based picosecond laser pump/x-ray probe experiments on chemical and biological systems in solution
}

\author{
Frederico A. Lima, ${ }^{1}$ Christopher J. Milne, ${ }^{1}$ Dimali C. V. Amarasinghe, ${ }^{1, \text { a) }}$ \\ Mercedes Hannelore Rittmann-Frank, ${ }^{1}$ Renske M. van der Veen, ${ }^{1, b}$ Marco Reinhard, ${ }^{1}$ \\ Van-Thai Pham, ${ }^{1, c)}$ Susanne Karlsson, ${ }^{1}$ Steven L. Johnson, ${ }^{2}$ Daniel Grolimund, ${ }^{2}$ \\ Camelia Borca, ${ }^{2}$ Thomas Huthwelker, ${ }^{2}$ Markus Janousch, ${ }^{2}$ Frank van Mourik, ${ }^{1}$ \\ Rafael Abela, ${ }^{3}$ and Majed Chergui ${ }^{1, d)}$ \\ ${ }^{1}$ Laboratoire de Spectroscopie Ultrarapide, Ecole Polytechnique Fédérale de Lausanne, ISIC, FSB, \\ 1015 Lausanne, Switzerland \\ ${ }^{2}$ Swiss Light Source, Paul Scherrer Institut, 5232 Villigen, Switzerland \\ ${ }^{3}$ SwissFEL, Paul Scherrer Institut, 5232 Villigen, Switzerland
}

(Received 28 April 2011; accepted 23 May 2011; published online 27 June 2011)

\begin{abstract}
We present the extension of time-resolved optical pump/x-ray absorption spectroscopy (XAS) probe experiments towards data collection at $\mathrm{MHz}$ repetition rates. The use of a high-power picosecond laser operating at an integer fraction of the repetition rate of the storage ring allows exploitation of up to two orders of magnitude more x-ray photons than in previous schemes based on the use of $\mathrm{kHz}$ lasers. Consequently, we demonstrate an order of magnitude increase in the signal-to-noise of time-resolved XAS of molecular systems in solution. This makes it possible to investigate highly dilute samples at concentrations approaching physiological conditions for biological systems. The simplicity and compactness of the scheme allows for straightforward implementation at any synchrotron beamline and for a wide range of x-ray probe techniques, such as time-resolved diffraction or x-ray emission studies. ( 2011 American Institute of Physics. [doi:10.1063/1.3600616]
\end{abstract}

\section{INTRODUCTION}

Over the past 10 years, there have been huge efforts aimed at investigating ultrafast photoinduced structural changes in molecules, crystals, materials, and proteins using structural probes such as electron and x-ray diffraction, electron microscopy, and x-ray absorption spectroscopy in a pump-probe scheme. ${ }^{1}$ The goal is to retrieve the structural dynamics of the systems on the atomic scales of space (sub- $\AA$ ) and time (femtoseconds to picoseconds). Ultrafast electron diffraction and microscopy are making rapid progress in following the structural dynamics of gas phase molecules, materials, thin films, and surfaces. ${ }^{1}$ Ultrafast x-ray diffraction has found many applications including the study of coherent phonons $^{2,3}$ and phase transitions in solid materials, ${ }^{4}$ while the first x-ray diffraction study on protein crystals has been achieved with 100 ps time resolution. ${ }^{5}$ For the case of chemical reactions in disordered media such as liquids, which is the medium wherein most chemical and biological reactions take place, x-ray scattering has been used in the $>100$-ps time scale ${ }^{6,7}$ but due to the sensitivity of the technique to all atoms in the sample and the complexity of processes occurring on this time scale in both solvent and solute, the analysis of the data is nontrivial. The chemical selectivity of $\mathrm{x}$-ray absorption spectroscopy (XAS) makes it ideal as a

a) Present address: Department of Chemical Physics, Lund University, SE-22100 Lund, Sweden.

b) Present address: California Institute of Technology, Pasadena, California 91125, USA.

c) Present address: Pacific Northwest National Laboratory, Richland, Washington 99352, USA.

d)Electronic mail: majed.chergui@epfl.ch. local probe, and allows retrieval of both the local geometric structure and the electronic environment around a given atom via analysis of the extended x-ray absorption fine structure (EXAFS) and the x-ray absorption near-edge spectroscopy (XANES) regions of the spectrum. This unique combination provides information about the electronic changes that drive the subsequent structural dynamics as well as information on the structural changes themselves. ${ }^{1,8-13}$

To date, picosecond optical pump/x-ray probe XAS experiments ${ }^{8,14-28}$ have been performed with the pump laser operating at $\mathrm{kHz}$ repetition rates in order to take advantage of the high pulse energies available from commercially available amplified laser systems ( $>1 \mathrm{~mJ} /$ pulse). In contrast to this, synchrotron $\mathrm{x}$-ray pulses are generally delivered at $\mathrm{MHz}$ repetition rates by the storage ring. The experiments typically make use of a fast detector to only measure the x-ray pulses generated by an isolated "camshaft" electron bunch of the hybrid filling mode available at third-generation synchrotron sources (see Fig. 1) and are usually based on recording the transient absorption on a pulse-to-pulse basis. The data acquisition is performed in such a way that the x-ray absorption signal of the sample is recorded at twice the repetition rate of the pump laser using gated detectors, with one $\mathrm{x}$ ray absorption signal corresponding to the laser-excited sample and the next to the unexcited sample. This scheme has proven capable of measurements limited only by the shot noise of the synchrotron source. ${ }^{17,18}$ Its main drawback is that while the excitation laser pulses occur at $\mathrm{kHz}$ repetition rates, the synchrotron pulses occur at $\mathrm{MHz}$ repetition rates, which means that typically $10^{3} \mathrm{x}$-ray pulses are unused. This reduced $\mathrm{x}$-ray flux is a major limiting factor on 
the achievable signal-to-noise ratio $(\mathrm{S} / \mathrm{N})$ of the experiments, which not only reduces the accuracy of the structural analysis but also places a restriction on samples that can be measured with a solubility in the range of tens to hundreds of $\mathrm{mM}$

In order to exploit all the available camshaft x-ray pulses, it would be necessary to use a pump laser that runs at half the repetition rate of the synchrotron source. At the Swiss Light Source (SLS, Paul Scherrer Institut, Villigen, Switzerland), this corresponds to a repetition rate of $1.04 \mathrm{MHz}$, which would require a laser at $520 \mathrm{kHz}$. Provided the conditions (laser fluence, incident x-ray flux per pulse, sample concentration, thickness, etc.) are similar to those of the 1 $\mathrm{kHz}$ experiments and assuming that the predominant source of noise is the shot noise of the x-ray source, an increase of $\sqrt{520} \approx 23$ in $\mathrm{S} / \mathrm{N}$ should be expected, resulting in significantly shorter data acquisition times and expanding the applicability of the technique to the study of dilute liquid-phase systems.

Previous attempts to implement a high-repetition rate pump-probe scheme at synchrotrons were made by Widdra et al. ${ }^{29,30}$ who used a $\mathrm{Nd}: \mathrm{YVO}_{4}$ oscillator $(1064 \mathrm{~nm}, 200 \mathrm{~nJ}$, $14 \mathrm{ps}$ ) with a pulse-picker operating at $1.25 \mathrm{MHz}$ to match the single-bunch repetition rate at the BESSY synchrotron (Berlin, Germany) for time-resolved core-level photoemission studies of surfaces. Stern et al. ${ }^{31,32}$ used an amplified Titanium:Sapphire laser source (800 nm, $3 \mu \mathrm{J}, 100 \mathrm{fs}$ ) operating at $272 \mathrm{kHz}$ at the APS (Advanced Photon Source, Argonne, USA) to study laser-induced melting of Germanium films. The disadvantage of using high-repetition rate excitation with solid samples is the sample damage resulting from the high average power. For liquid solutions, high repetition rate excitation is ideal since the flowing sample is continuously refreshed, but this has so far not been attempted. Given that the main limitation in the picosecond optical pump/XAS probe studies at $1 \mathrm{kHz}$ is the low X-ray flux, it seems worthwhile to extend the pump/probe scheme to data collection at higher repetition rates.

Here we report on a portable experimental setup for ps XAS studies at both the hard x-ray microXAS beamline and the tender X-ray PHOENIX I beamline of the Swiss Light Source. It uses a compact ps pump laser with variable repetition rate, widening the potential application of picosecond $\mathrm{x}$-ray experiments to the many diverse $\mathrm{x}$-ray techniques (absorption, emission, diffraction, scattering) available at synchrotrons. We demonstrate its performance by investigating the well characterized light-induced spin crossover process in $\left[\mathrm{Fe}(\text { bpy })_{3}\right]^{2+}$ (Ref. 33) and the oxidation state change in $\left[\mathrm{Ru}(\mathrm{bpy})_{3}\right]^{2+},{ }^{34}$ showing improved S/N for highconcentration samples and pump-probe signals at high dilutions. Additionally, as a demonstration of the new scheme on low concentration biological systems in physiological media, we report the results of a pump-probe XAS experiment on photoexcited carboxymyoglobin (MbCO).

\section{INSTRUMENTS AND METHODS}

The main elements required for a picosecond timeresolved XAS experiment will be briefly reviewed,

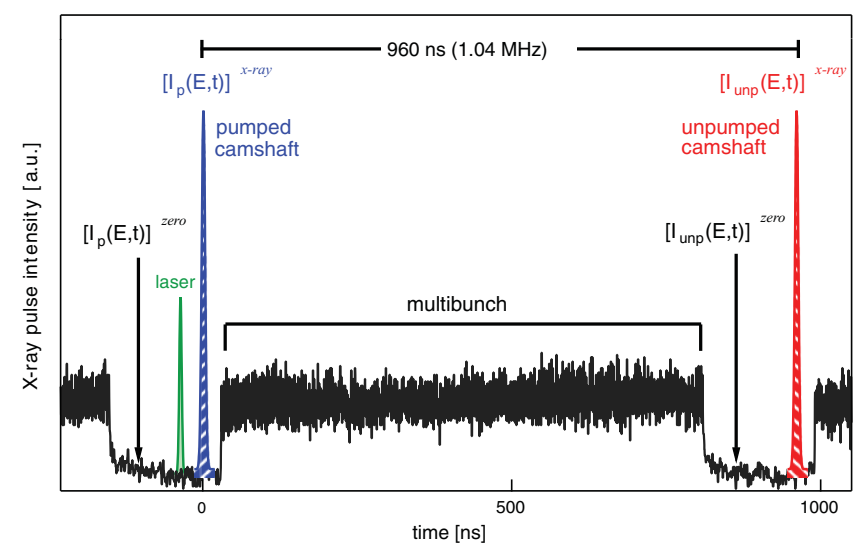

FIG. 1. (Color online) Electron filling pattern used at the SLS. In total, there are 480 possible buckets spaced 2 ns apart, of which 390 are filled with electrons (multibunch). Of the 90 remaining empty buckets, the camshaft pulse in bucket 465 is filled with four times more current than the average multibunch current. The ring repetition rate is $1.04 \mathrm{MHz}$, which sets an upper limit for the data acquisition rate of the experiments using the current hybrid filling mode.

highlighting the specifics of the $\mathrm{MHz}$ data acquisition scheme for comparison to $\mathrm{kHz}$ data acquisition. ${ }^{14,17,18}$

\section{A. X-ray source}

The probe pulses are derived from the camshaft electron bunch provided by the SLS during normal user operation. The isolated pulse is a result of the hybrid electron filling pattern used at the SLS (Fig. 1) which consists of 390 consecutive electron bunches separated by $2 \mathrm{~ns}$, called the multibunch, and an isolated electron bunch, called the camshaft pulse, which is placed within the empty gap of $180 \mathrm{~ns}$. The isolated single bunch has four times more current than the individual bunches in the multibunch structure and a duration of approximately 85 ps (FWHM). ${ }^{35}$ During normal user operation the ring current is $400 \mathrm{~mA}$ and the camshaft current is $4 \mathrm{~mA}$. The ring current is maintained to within $0.5 \%$ by use of top-up filling mode which injects electrons into the storage ring at regular intervals.

The reported experiments were conducted at two different beamlines at the SLS. The microXAS beamline, located in the long straight section X05L of the SLS ring, is equipped with a minigap in-vacuum undulator capable of generating x-rays from 4 to $23 \mathrm{keV}$ with a flux of approximately $10^{12}$ photons/s/0.015\% bandwidth. The photons are collimated vertically and focussed horizontally by a Rh-coated toroidal mirror and then energy selected over a range of bandwidths by a double-crystal, fixed exit monochromator (DCM) containing $\mathrm{Si}(111), \mathrm{Ge}(111)$, and $\mathrm{Si}(311)$ crystal pairs. An elliptical mirror pair in the Kirkpatrick-Baez (KB) geometry is located immediately before the experimental station, and is capable of focusing the $\mathrm{x}$-rays down to $<1 \times 1 \mu \mathrm{m}^{2}$ spot. $^{36}$

The PHOENIX I beamline covers the tender X-ray spectrum from $800 \mathrm{eV}$ to $8 \mathrm{keV}$. The photon source is an elliptical APPLE II undulator with a flux of $10^{11}$ photons $/ \mathrm{s} / 0.01 \%$ bandwidth. The beamline is equipped with a DCM containing $\mathrm{Si}(111)$ crystal pairs, for energies above $2.1 \mathrm{keV}$, and $\mathrm{KB}$ mirrors allowing for $\mu \mathrm{m}$ focal spots. 


\section{B. Laser source}

Since the time-resolution of the XAS experiments is generally limited by the synchrotron pulse duration (typically $85 \mathrm{ps}$ at the SLS), there is no advantage to using fs laser systems to excite the sample as done so far. In fact there are several disadvantages. These sources are amplified, which means they need both a large amount of space and substantial cooling. They are often outside the experimental hutch, implying beam transport over tens of meters to the sample, which results in an increased sensitivity to the laser pointing stability and the far-field laser mode. Here we use a compact, high-average power $\mathrm{Nd}: \mathrm{YVO}_{4}$ picosecond laser (Duetto, Time Bandwidth Products, Zürich) operating at variable repetition rate $(50 \mathrm{kHz}$ to $8 \mathrm{MHz})$, and producing $10 \mathrm{ps}$ pulses. This product is primarily aimed at industrial users meaning emphasis has been placed on turn-key operation and long-term stability. It delivers up to two orders of magnitude more energy per pulse than current high-repetition rate femtosecond oscillators, but still two orders of magnitude less energy per pulse than $\mathrm{kHz}$ amplified femtosecond systems. The Duetto laser system optimizes the amplifier stage diode pump current to extract the maximum possible pulse energy at any given repetition rate. When operated at half the repetition rate of the isolated camshaft pulse $(520 \mathrm{kHz})$ this results in $28 \mu \mathrm{J}$ per pulse at the fundamental wavelength, $1064 \mathrm{~nm}$. By frequency doubling and tripling one obtains $15 \mu \mathrm{J}$ per pulse at $532 \mathrm{~nm}$ and $6 \mu \mathrm{J}$ per pulse at $355 \mathrm{~nm}$. It is also possible to double the $532 \mathrm{~nm}$ light to obtain $266 \mathrm{~nm}$ light. The laser mode has an $\mathrm{M}^{2}$ value of 1.2 for both the doubled and tripled beams which permits it to be efficiently focussed to very small diameter spots, thus allowing similar fluences compared to the $\mathrm{kHz}$ experiments at modest beam diameters $(<50 \mu \mathrm{m})$.

The use of this pump laser offers three primary advantages with respect to amplified fs systems at $1 \mathrm{kHz}$ : (1) the longer pulse duration results in lower peak power, which minimizes sample damage and nonlinear effects, and generally results in more efficient sample excitation; (2) the fact that the pulse energy varies with the repetition rate allows both the excitation and the repetition rate to be tuned to the experimental requirements; and (3) Titanium:Sapphirebased amplified systems operate at $800 \mathrm{~nm}$, which can easily be converted into 400 and $266 \mathrm{~nm}$ light, while molecular systems typically absorb in the visible region of the spectrum (400-700 nm), making these amplified pulses a poor choice for sample excitation whereas the $532 \mathrm{~nm}$ wavelength available from the high-repetition rate laser is ideal. For experiments on species with very long-lived excited-state lifetimes a "slow-difference" scan mode can be used in which the transient data are no longer collected by the pulse-topulse difference method, but as a difference of the average of 1 million x-ray measurements with laser on, and second average of 1 million x-ray measurements with the laser off. This alternative data collection mode will be detailed in Sec. IV C.

\section{Synchronization and timing control}

Overall stability and synchronization between the pump and probe sources are crucial for the success of any timeresolved experiments. The pump laser pulses have to be accurately synchronized to the $\mathrm{x}$-ray probe pulses in order to have control of the relative temporal delay between them. Here we adopted a similar synchronization and timing control scheme used for previous optical pump/x-ray probe experiments, ${ }^{17,18}$ which has previously proven to work reliably over the time required for the experiments. A simplified scheme of the synchronization and the timing control is shown in Fig. 2.

This is achieved by exploiting the intrinsic synchronization of the radio frequency (RF) master clock of the SLS with

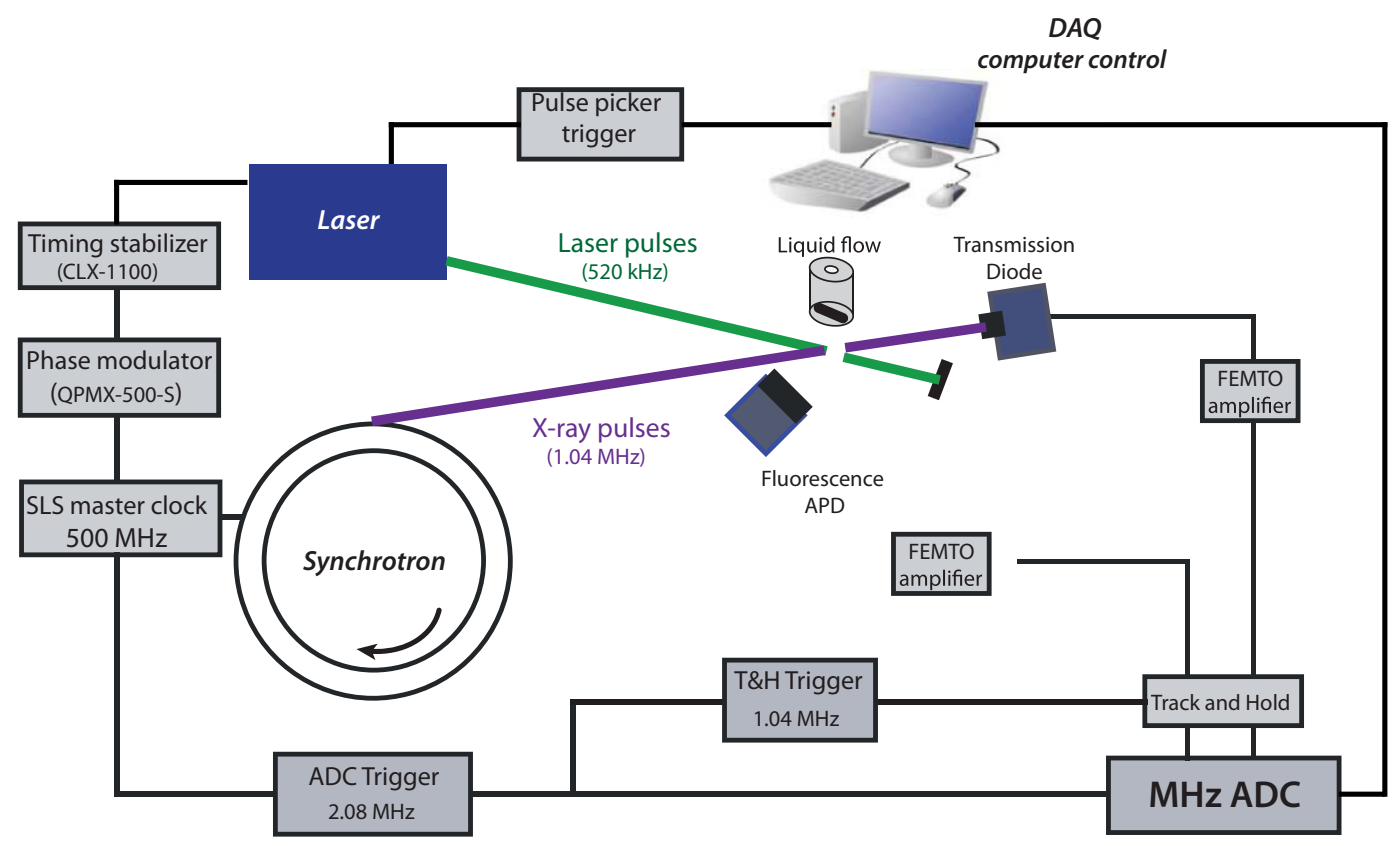

FIG. 2. (Color online) Diagram of the high-repetition rate pump-probe setup, see text for details. 
the $\mathrm{x}$-ray pulses. This master clock is synchronized to the $500 \mathrm{MHz}$ signal of the RF cavities which is, in turn, responsible for creating the potential wells inside the storage ring, thus providing the time structure of the generated radiation. If a stable phase relationship between the RF and the laser oscillator pulses is established, synchronization is achieved. The relative phase stabilization is done via a commercially purchased system (CLX-1100 timing stabilizer, Time Bandwidth Products), which locks the phase of the Duetto laser oscillator to the SLS master RF with a timing jitter of less than $400 \mathrm{fs}$.

The relative time delay between the $\mathrm{x}$-rays and laser pulses can be adjusted via a computer controlled timing system, which is integrated into the data acquisition. The timing of the laser pulse is controlled by synchronous scanning of the trigger for the Duetto pulse picker and an RF phase modulator (QPMX-500-S, I. F. Engineering). The phase modulator allows precise control over the relative phase of the oscillator with respect to that of the RF, thus changing the relative time delay between the laser and x-ray pulses with a few ps precision.

\section{Detection and data acquisition}

The employed data collection strategy is similar to that used for previous experiments, ${ }^{11,17,18}$ with the important difference that the data acquisition rate is increased to $2 \mathrm{MHz}$. Briefly, the XAS signal at a specific x-ray energy and pumpprobe time delay is recorded at twice the laser repetition rate, alternating between the signal from the excited sample and from the unexcited sample $1 \mu$ s later (see Fig. 1). In addition, a zero measurement is made for every $\mathrm{x}$-ray measurement by reading the detector signal in the fill pattern gap where no X-rays are present. This electronic zero level is then subtracted off the corresponding $x$-ray signal to compensate for any drift in the data acquisition baseline over time. The signals provided to the user correspond to the pumped XAS signal $\left(\left[I_{p}\right]^{\mathrm{x} \text {-ray }}-\left[I_{p}\right]^{\text {zero }}\right)$, the unpumped XAS signal $\left(\left[I_{u n p}\right]^{\mathrm{x}-\mathrm{ray}}-\left[I_{\text {unp }}\right]^{\mathrm{zero}}\right)$ and the pulse-to-pulse difference signal of pumped-unpumped with the zeroes being ignored as the electronic baseline will have no time to drift during the $1 \mu \mathrm{s}$ separating the two $\mathrm{X}$-ray measurements $\left(\left[I_{p}\right]^{\mathrm{x}-\mathrm{ray}}-\left[I_{\text {unp }}\right]^{\mathrm{x}-\text { ray }}\right)$. The data acquisition scheme is shown in Fig. 2.

Detectors for a time-resolved XAS experiment must fulfill three main requirements: (a) they should be fast enough to isolate the $\mathrm{x}$-ray pulses that come solely from the camshaft bunch, (b) they must generate sufficient signal when exposed to a range of $x$-ray energies, and (c) they must have linear response over the range of $x$-ray flux used. In the present setup, the x-ray pulses are measured using two different types of fast detectors: for fluorescence signals large-area avalanche photodiodes (C30703F, PerkinElmer) with a $1 \mathrm{~cm} \times 1 \mathrm{~cm}$ active area are used when the intrinsic gain of the device is necessary to measure signals down to the single x-ray photon level. In transmission, silicon photodiodes are used (AXUV20HS1, International Radiation Detectors) where device linearity over several orders of magnitude of current becomes critically important. Both types of detectors have rise times $<5 \mathrm{~ns}$. The detectors are shielded with $25 \mu \mathrm{m}$ thick Be foils to protect them from scattered laser light. The detector signal is then amplified using broad-bandwidth (80-200 MHz) current-tovoltage amplifiers (FEMTO DHPCA-100) which allow the signal to be transferred to the data acquisition system with a minimum of additional noise. We use track-and-hold circuits (AD9100, Analog Devices) to sample the amplified signal on the maximum of the camshaft pulse. This level is then held for sufficient time for the fast analog-to-digital card to sample the signal level. The digitizer is an eight-channel ADC/digitizer board (Struck Innovative System GmbH, model SIS3302) with a sampling rate of up to $100 \mathrm{MHz}$ and 16 bit resolution, capable of sampling up to 8 channels in parallel for each given trigger. The ADC is housed in a virtual machine environment (VME) crate together with the hardware for generating all the timing signals. Triggers are required for the $\mathrm{ADC}$ at $2.08 \mathrm{MHz}$ to read the zero signal and the $\mathrm{x}$-ray signal, the laser pulse picker at $520 \mathrm{kHz}$ (or some even sub-multiple of the $1.04 \mathrm{MHz} x$-ray frequency), and the track-and-hold circuits at $1.04 \mathrm{MHz}$. In addition two marker signals are generated and digitized in parallel with the data channels to indicate if a signal originates from the laser-excited or from the unexcited sample and if the signal is an x-ray measurement or a zero measurement. The VME crate uses these marker signals to sort the data prior to performing the signal averaging.

The reported measurements are performed in transmission and fluorescence yield (FY) modes simultaneously. Depending on the sample solubility and optical density one can adjust the concentration in order to optimize the signal for either mode. ${ }^{8}$ For the hard-x-ray experiments the incident $x$-ray intensity $\left(I_{0}\right)$ was also recorded by measuring the fluorescence from a thin Cr foil using an APD. Recording the incoming $\mathrm{x}$-ray flux on a pulse-to-pulse basis allows the normalization of incoming x-ray fluctuations due to monochromator imperfections or changes due to the storage ring. Moreover, normalization of the unexcited spectra to the incident flux yields the static XAS of the sample. Note that the transient difference measurement does not in general require $I_{0}$ normalization since the incident x-ray flux does not change on a $1 \mu \mathrm{s}$ timescale.

With the laser operating at $520 \mathrm{kHz}$, two million measurements are performed over the course of 1 s: 500000 pumped x-rays, 500000 pumped zeroes, 500000 unpumped $\mathrm{x}$-rays, and 500000 unpumped zeroes. These signals are then sorted according to the markers, the requisite calculations are performed and then each of the three signals is averaged, returning to the scanning PC the averaged data and the standard error of the pumped/unpumped/difference measurement for each of the ADC channels.

The time-dependent transmission transient XAS signal is defined as

$$
\Delta A^{T}(E, t)=\ln \left(\frac{\left[I_{u n p}^{T}(E)\right]^{\text {x-ay }}-\left[I_{u n p}^{T}(E)\right]^{\text {zero }}}{\left[I_{p}^{T}(E, t)\right]^{\text {x-ay }}-\left[I_{p}^{T}(E)\right]^{\text {ero }}}\right) .
$$

The time-dependent fluorescence transient XAS signal is defined as 


$$
\Delta A^{F}(E, t)=\frac{\left(\left[I_{p}^{F}(E, t)\right]^{\mathrm{x} \text {-ay }}-\left[I_{p}^{F}(E, t)\right]^{\text {zero }}\right)-\left(\left[I_{\text {unp }}^{F}(E)\right]^{\mathrm{x} \text {-ray }}-\left[I_{\text {unp }}^{F}(E)\right]^{\text {zero }}\right)}{I_{0}(E)}
$$

The subscripts unp and $p$ stand for the ground-state (unpumped) or excited (pumped) sample, respectively. $I_{0}$ represents the incoming x-ray intensity, $I^{T}$ stands for the transmitted, and $I^{F}$ for the fluorescence signals. The superscript $x$-ray indicates that the signal was recorded with the presence of $\mathrm{x}$-rays and the superscript zero indicates that it was recorded without any $\mathrm{x}$-rays, representing the electronic background signal of the detection system.

In $1 \mathrm{kHz}$ experiments, this data acquisition methodology delivers results at the shot noise limit of the $\mathrm{x}$-ray source. ${ }^{17,18}$ In this limit, the $\mathrm{S} / \mathrm{N}$ increases linearly with the fraction of excited species, while it increases with $\sqrt{n}$ of the number of accumulated x-ray photons, and thus the repetition rate of the experiment. ${ }^{8,37}$ In the present experiment, the repetition rate was increased by a factor of 520 , meaning that the expected increase on the $\mathrm{S} / \mathrm{N}$ ratio is $\sqrt{520} \approx 23$, if all other parameters (x-ray flux, excitation yield, etc.) are considered unchanged.

To test the linearity of the photodiode used as transmission detector a series of measurements of the direct x-ray flux were taken, attenuating it by placing successive thin aluminium foils in the incoming beam. The $\mathrm{x}$-ray intensity was recorded directly as the diode current, the track-and-hold output, and the data acquisition digitized signal. Assuming a constant incoming intensity, which is a reasonable approximation for the SLS since it operates in top-up mode, we expect the transmitted signal to follow the Lambert-Beer law. In other words, the detector should behave linearly with respect to the incoming intensity. Indeed, the Si diode signal is linearly proportional to the incoming x-ray flux (see Fig. 3), even when the full flux of the beamline, $10^{12}$ photons/s, is used.

\section{E. Spatial and temporal overlap of laser and x-rays}

The spatial overlap between laser and $\mathrm{x}$-rays was obtained by placing a $50 \mu \mathrm{m}$ diameter, $25 \mu \mathrm{m}$ thick tungsten pinhole in the sample position. The $\mathrm{x}$-ray position and size can be determined by scanning the pinhole through the x-rays using a two-dimensional translation stage $(0.1 \mu \mathrm{m}$ resolution), while monitoring the transmission intensity (see Fig. 4). Once the $\mathrm{x}$-ray position is found, the pinhole is moved to that position and the attenuated laser beam is then guided through the pinhole and its position is optimized via a motorized laser mirror. Figure 4 shows example scans of the horizontal and vertical beam profiles of the laser and x-rays at the sample position. The x-ray spot size was determined to be less than $50 \mu \mathrm{m}$ in both dimensions (FWHM). The beamline $\mathrm{x}$-ray image monitor indicates that the x-ray beam is focused down to $\sim 40 \mu \mathrm{m}$. The laser beam size was made larger than the $\mathrm{x}$-ray spot ( $85 \mu \mathrm{m}$ horizontally and $65 \mu \mathrm{m}$ vertically), to ensure a uniformly excited sample and to facilitate the overlap of the pump and probe beams.

To set the temporal overlap a fast windowless photodiode having a rise time of 700 ps (AXUVHS5, International Radiation Detectors) was placed at the sample position. Using a $2.25 \mathrm{GHz}$ oscilloscope (Agilent Infiniium) the relative laser and x-ray temporal delay could be determined. The laser pulse-picker timing was then adjusted to shift the laser timing in coarse steps of $12 \mathrm{~ns}$, and then the phaseshifter was used for finer time steps. In general the two pulses can be overlapped to within 200 ps which is sufficient for samples where the excited state lifetime is $>200$ ps. For $\left[\mathrm{Fe}(\mathrm{bpy})_{3}\right]^{2+}$ the excited state lifetime is about $650 \mathrm{ps}^{20}$ while

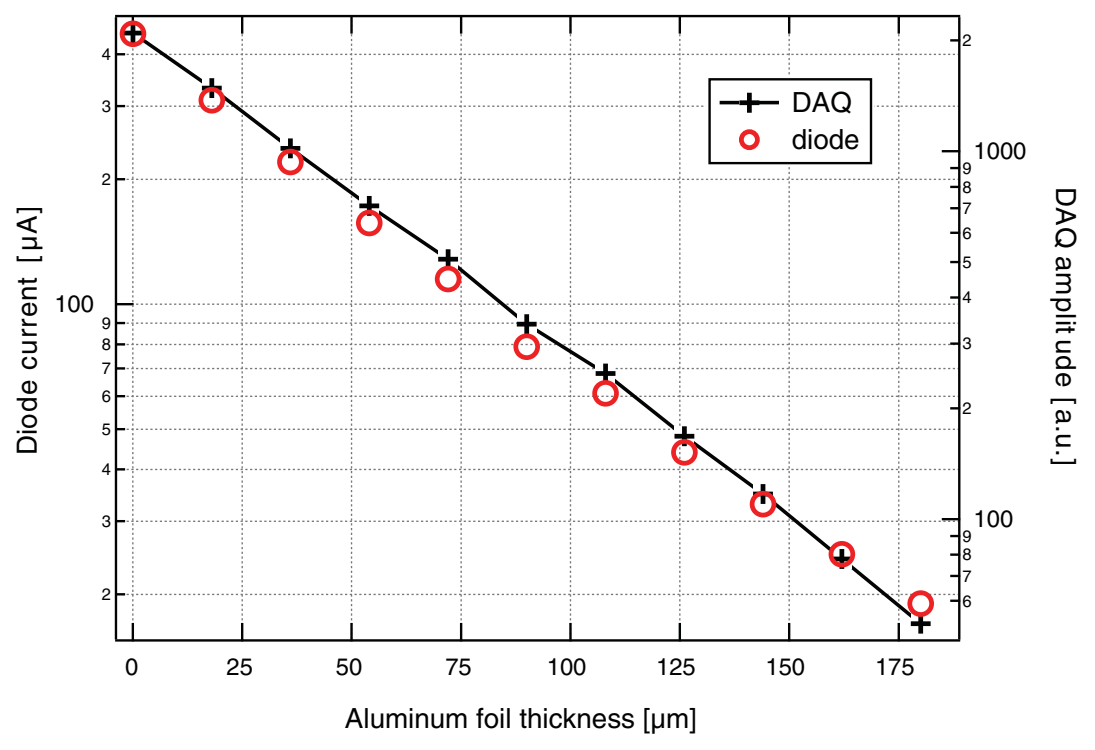

FIG. 3. (Color online) X-ray transmission signal (at $7.05 \mathrm{keV}$ ) measured by a fast diode. Left axis shows the diode current (red circles) while the right axis shows the digitized signal amplitude (black crosses). The flux was attenuated by placing aluminium foils of varying thickness in the beam. On a logarithmic scale the signal shows a linear dependence on absorber pathlength over the full range of x-ray flux indicating that the diode and DAQ are linear. 

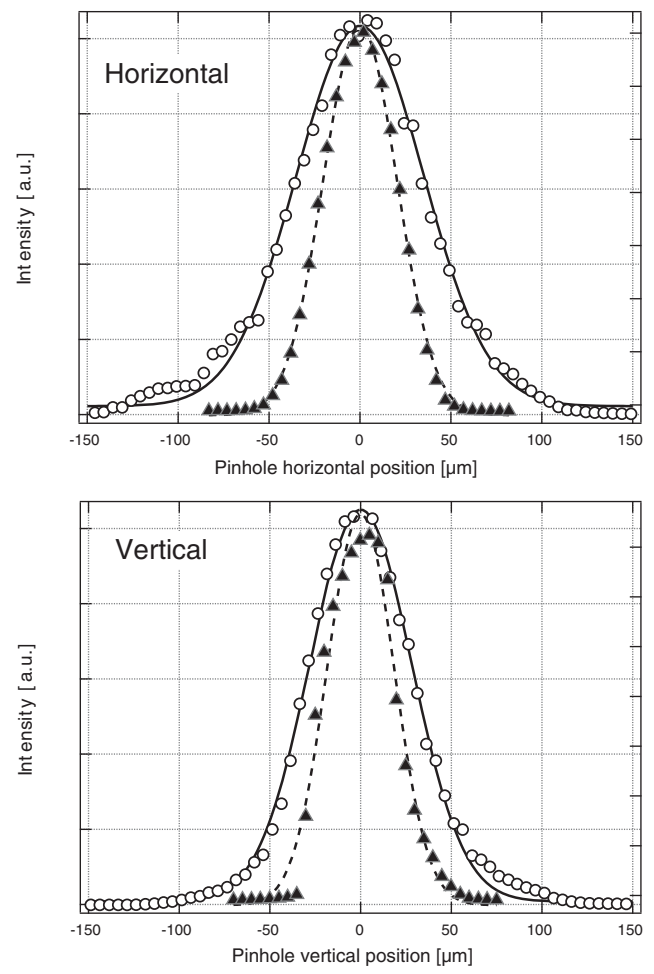

FIG. 4. Laser (circles) and x-ray (triangles) beam profiles scanned through a $50 \mu \mathrm{m}$ diameter pinhole. Solid and dashed lines are Gaussian fits.

for $\left[\mathrm{Ru}(\mathrm{bpy})_{3}\right]^{2+}$ the excited state lifetime is about $500 \mathrm{~ns}$, with a strong dependence on sample concentration and solvent oxygen concentration. ${ }^{38}$

\section{F. Electronic noise investigation}

In order to assess the sensitivity of the $\mathrm{MHz}$ data acquisition system and to investigate any sources of electronic noise, we recorded the digitized individual output signals in transmission and fluorescence modes, corresponding to the 2 million samples, or approximately $1 \mathrm{~s}$ integration time. Figure 5 shows a histogram of the distribution of 500000 zero measurements and $500000 \mathrm{x}$-ray measurements (see Fig. 1) for an unpumped signal of a $7 \mathrm{mM}$ aqueous solution of $\left[\mathrm{Fe}(\mathrm{bpy})_{3}\right]^{2+}$ recorded at $7.125 \mathrm{keV}$. The fact that the transmission zero measurement distribution is narrower than the transmission x-ray measurement distribution shows that the electronic noise is smaller than the photon noise. The fluorescence signal shows similar characteristics with the additional feature that the Poisson distribution of the photon-counting events can clearly be resolved. ${ }^{39}$

\section{SAMPLES AND SAMPLE ENVIRONMENT}

Iron(II)-tris $\left(2,2^{\prime}\right)$-bipyridine chloride hexahydrate $\left(\left[\mathrm{Fe}(\mathrm{bpy})_{3}\right] \mathrm{Cl}_{2} \cdot\left(\mathrm{H}_{2} \mathrm{O}\right)_{6}\right)$ was dissolved in deionized water at concentrations ranging from 1 to $70 \mathrm{mM}$. The sample solutions were circulated using a magnetically driven gear pump through a sapphire nozzle creating a $100 \mu \mathrm{m}$ thick jet, approximately $5 \mathrm{~mm}$ wide at the nozzle exit. The sample was excited with $532 \mathrm{~nm}$ pulses from the Duetto laser, at $520 \mathrm{kHz}$ repetition rate and focussed to a $75 \mu \mathrm{m}$ spot size (FWHM). Laser fluences ranging from 13 to $400 \mathrm{~mJ} / \mathrm{cm}^{2}$ were used. All measurements were performed in air.

Ruthenium(II)-tris (2, 2')-bipyridine chloride hexahydrate $\left(\left[\mathrm{Ru}(\mathrm{bpy})_{3}\right] \mathrm{Cl}_{2} \cdot\left(\mathrm{H}_{2} \mathrm{O}\right)_{6}\right)$ was dissolved in deionized water at $80 \mathrm{mM}$ concentration. The sample solution was handled identically to $\left[\mathrm{Fe}(\mathrm{bpy})_{3}\right]^{2+}$. It was excited at both 355 and $532 \mathrm{~nm}$ at a repetition rate of $520 \mathrm{kHz}$. The laser spot size used was $75 \mu \mathrm{m}$ (FWHM) which results in a fluence of $115 \mathrm{~mJ} / \mathrm{cm}^{2}$ for the $532 \mathrm{~nm}$ experiments and $86 \mathrm{~mJ} / \mathrm{cm}^{2}$ for the $355 \mathrm{~nm}$ experiments. The experiments were performed in a chamber under an 800 mbar atmosphere of $80 \%$ He and $20 \% \mathrm{~N}_{2}$.

Lyophilized myoglobin $(\mathrm{Mb})$ from equine skeletal muscle (Sigma, 95\%-100\%, salt free) was used without further purification to prepare liquid samples of ferric myoglobin (metMb) by dissolving the powder in de-gassed sodium phosphate buffer solution with $\mathrm{pH} 7$ and then reducing it to the ferrous state (deoxyMb) under anaerobic conditions. To produce carboxymyoglobin (MbCO), the deoxyMb was bubbled with $\mathrm{CO}$ gas for approximately 20 minutes. During the experiments, the sample reservoir was kept under carbon monoxide atmosphere by flowing $\mathrm{CO}$ gas over the sample. Complete conversion to the ligated form and sample integrity were monitored by UV-Vis spectra collected simultaneously with the transient XAS experiments. The final carboxymyoglobin sample concentration was around $2 \mathrm{mM}$. It was excited with $532 \mathrm{~nm}$ focussed into a laser spot size of $75 \mu \mathrm{m}$ (FWHM), at a fluence of $125 \mathrm{~mJ} / \mathrm{cm}^{2}$.

Static XAS spectra of myoglobin were measured on a $2 \mathrm{mM}$ solution circulating through a quartz capillary having $2 \mathrm{~mm}$ path length and $50 \mu \mathrm{m}$ walls using a peristaltic pump. The sample reservoir was kept in an ice bath to prevent degradation. The static XAS of the myoglobin samples were collected in both transmission and fluorescence mode; however, the transmission spectra did not show any clear signal due to the low concentration of the sample. The incoming and transmitted x-ray flux were measured using ion chambers filled with helium at approximately 1 bar, while the fluorescence was measured using a single-element Silicon drift detector (AXAS-SDD10-138500, Ketek). For the time-resolved measurements of $\mathrm{MbCO}$ the liquid sample was flowed through the same $100 \mu \mathrm{m}$ thick jet previously described. It was possible to use an exposed jet in open atmosphere because the affinity of myoglobin to CO is very high ${ }^{40,41}$ which makes the sample stable even in oxygen rich environments.

\section{RESULTS}

\section{A. Iron-tris bipyridine}

As a test of the high repetition rate scheme and to estimate the increase in $\mathrm{S} / \mathrm{N}$ compared to the $1 \mathrm{kHz}$ experiments we used $\left[\mathrm{Fe}(\mathrm{bpy})_{3}\right]^{2+}$ dissolved in water, the photocycle of which was previously fully characterized using a combination of ultrafast optical spectroscopic techniques and ps and fs XAS. ${ }^{20,33,42-45}$ Laser excitation of the singlet ground state at $532 \mathrm{~nm}$ leads to population of a singlet 

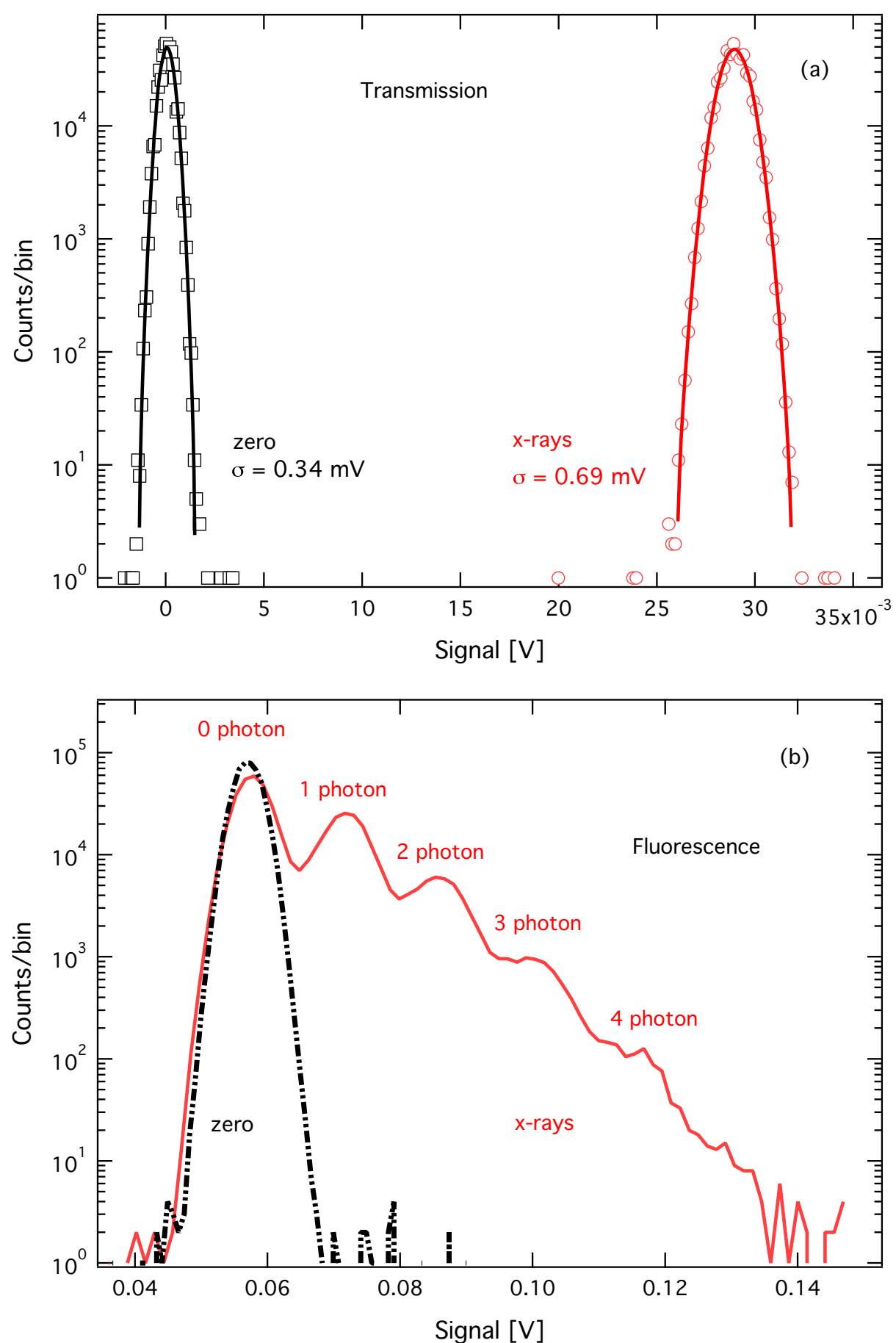

FIG. 5. (Color online) Pulse-height distribution of $1 \times 10^{6}$ samples recorded in transmission mode (a) and fluorescence mode (b) at $7.125 \mathrm{keV}$ for a $7 \mathrm{mM}$ sample of $\left[\mathrm{Fe}(\mathrm{bpy})_{3}\right]^{2+}$. Gaussian fits to the histograms are shown as lines for the transmission signals. Note the clear peaks from multi-photon events in the fluorescence signal (0.56 photons/pulse).

metal-to-ligand-charge-transfer $\left({ }^{1} \mathrm{MLCT}\right)$ state, which then decays by ultrafast intersystem crossing to the lowest excited high-spin (HS) quintet state ${ }^{5} \mathrm{~T}_{2}$, resulting in the Fe-N bond increasing by $\sim 0.2 \AA$ from the low-spin ground state to the HS excited state. This bond elongation was determined by Gawelda et al. ${ }^{20,43}$ by analyzing the picosecond XANES and EXAFS transient spectra recorded at the $\mathrm{Fe} \mathrm{K}$ absorption edge (7 keV) using the previous scheme of $\mathrm{kHz}$ data collection. These results serve to benchmark the present scheme.
For accurate comparison, we used a $25 \mathrm{mM}$ concentration of aqueous $\left[\mathrm{Fe}(\mathrm{bpy})_{3}\right]^{2+}$ as in the $\mathrm{kHz}$ experiments. ${ }^{20}$ It should be kept in mind that it is not possible to strictly compare the two experiments because of the $532 \mathrm{~nm} / 10 \mathrm{ps}$ excitation here versus the $400 \mathrm{~nm} / 100 \mathrm{fs}$ in the $\mathrm{kHz}$ experiments. However, given the ultrafast departure of population from the MLCT states, which we previously determined to be $\sim 150 \mathrm{fs},{ }^{44,45}$ and the fact that there is no known excited-state absorption at $532 \mathrm{~nm},{ }^{33,42}$ the difference in excitation pulse 

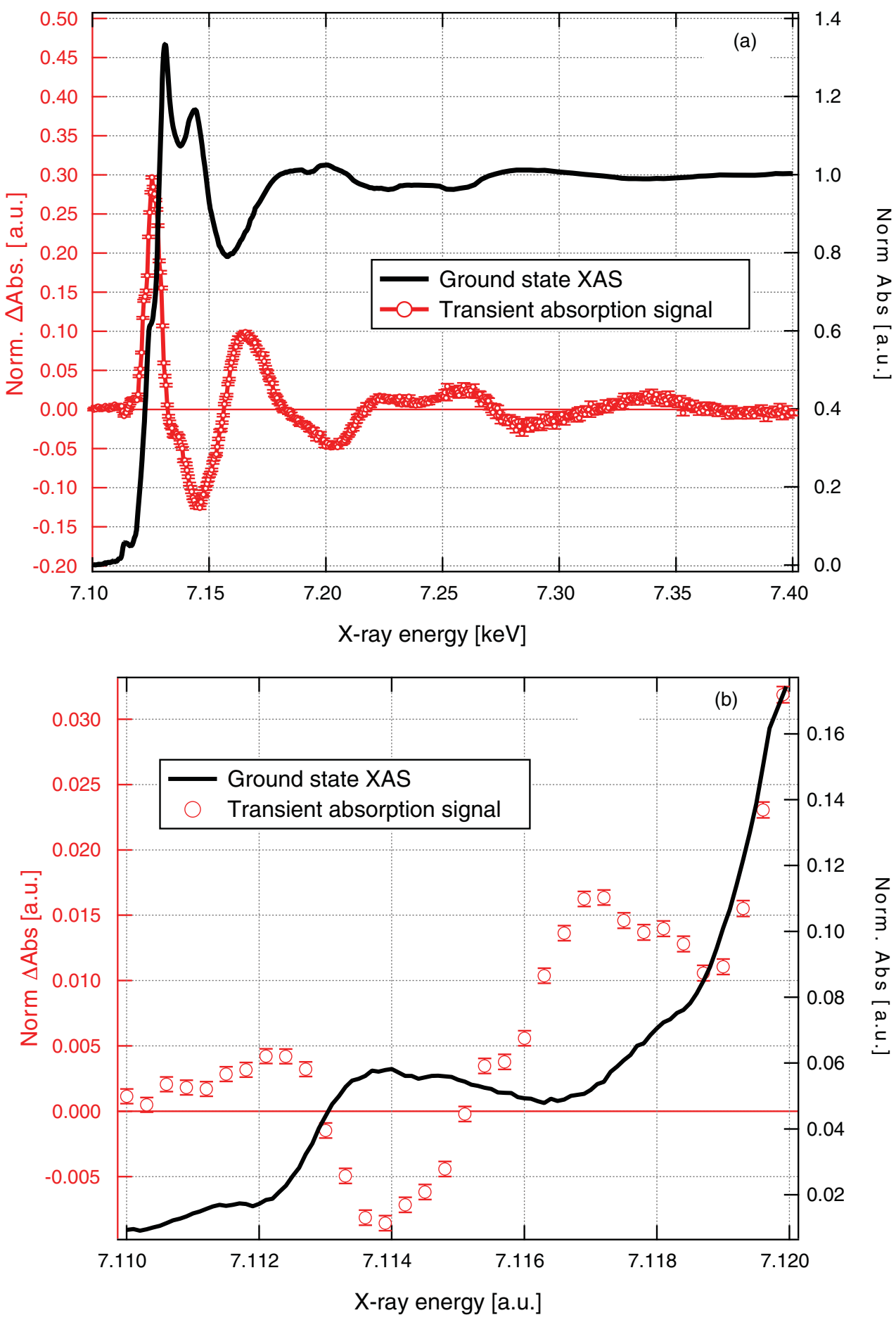

FIG. 6. (Color online) (a) The near-edge XAS of a $25 \mathrm{mM}$ aqueous solution of $\left[\mathrm{Fe}(\mathrm{bpy})_{3}\right]^{2+}$ collected in fluorescence yield mode showing the ground-state spectrum (black line) and the average of 11 transient XAS scans measured using the high-repetition rate setup (red markers) and a fluence of $100 \mathrm{~mJ} / \mathrm{cm}^{2}$. (b) Zoom of the ground state pre-edge features (black line) and the transient XAS (red circles) in the same energy range using a pump fluence of $200 \mathrm{~mJ} / \mathrm{cm}^{2}$.

width should not affect the results. However, the absorption cross section is approximately three times higher at $532 \mathrm{~nm}$ than at $400 \mathrm{~nm}^{42}$

Due to the lower pulse energy of the Duetto laser compared to amplified $\mathrm{kHz}$ laser systems, it was necessary to tightly focus the laser beam in order to maintain a comparable laser fluence on the sample. In the previous $\mathrm{kHz}$ experiments ${ }^{20}$ the laser focus was around $200-250 \mu \mathrm{m}$, while the present scheme makes use of 60-85 $\mu \mathrm{m}$ laser spot sizes.
Consequently, the x-rays also needed to be more tightly focussed (see Fig. 4).

Figure 6(a) shows both the ground state XAS of a $25 \mathrm{mM}$ solution of $\left[\mathrm{Fe}(\mathrm{bpy})_{3}\right]^{2+}$ and the average of 11 scans of the transient XAS measured 50 ps after excitation at $532 \mathrm{~nm}$ using the high-repetition rate system and a fluence of $100 \mathrm{~mJ} / \mathrm{cm}^{2}$. The latter agrees very well with the transient previously recorded at $1 \mathrm{kHz}^{20,39}$ At the maximum of the transient signal, $7.126 \mathrm{keV}$ (all subsequent $\mathrm{S} / \mathrm{N}$ ratios 

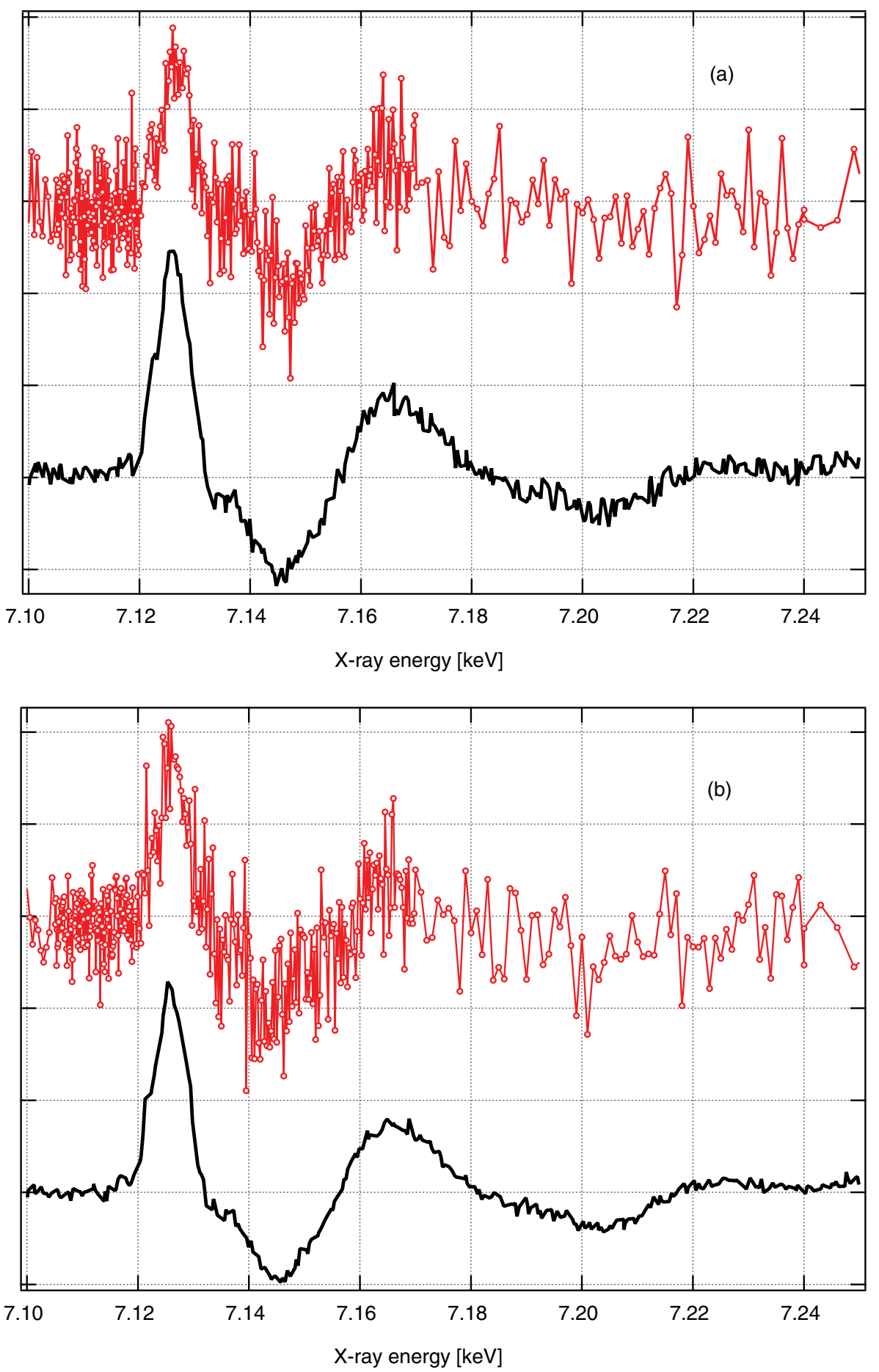

FIG. 7. (Color online) Representative single scans of the near-edge transient XAS of a $25 \mathrm{mM}$ aqueous solution of $\left[\mathrm{Fe}(\mathrm{bpy})_{3}\right]^{2+}$, in transmission (a) and fluorescence (b) modes, collected using both the $\mathrm{kHz}$ (red circles) and high-repetition rate (black line) data acquisition techniques.

refer to the signal at this energy), we obtain a $\mathrm{S} / \mathrm{N} \simeq 158$ in fluorescence mode, and 142 transmission mode. This translates to a $\mathrm{S} / \mathrm{N} \simeq 45$ per scan in both modes. Increasing the laser fluence to $200 \mathrm{~mJ} / \mathrm{cm}^{2}$, a value closer to that used in the $\mathrm{kHz}$ experiments, the $\mathrm{S} / \mathrm{N}$ per scan increases to $\sim 70$ in both modes. Comparisons of single scans taken using the two different techniques are shown in Fig. 7.

Since the Fe K-edge XAS spectrum of the laser-excited $\left[\mathrm{Fe}(\mathrm{bpy})_{3}\right]^{2+}$ is known, ${ }^{20}$ it is possible to extract the excitedstate population by subtracting the unexcited spectrum (low spin) from the laser-excited spectrum (high spin). The excited state spectrum is related to the measured transient XAS, the fraction of excited species and the unexcited spectrum via the following equation: ${ }^{20,43}$

$$
\Delta \operatorname{Abs}(E, t)=f(t)\left[\mathrm{A}_{p}(E, t)-A_{\text {unp }}(E)\right],
$$

with $f(t)$ being the fractional population of the excited state at a given time delay, $A_{p}$ and $A_{u n p}$ the laser pumped and unpumped normalized XAS spectra of the sample being studied, respectively. We then extract an excitation yield of $60 \%$ 


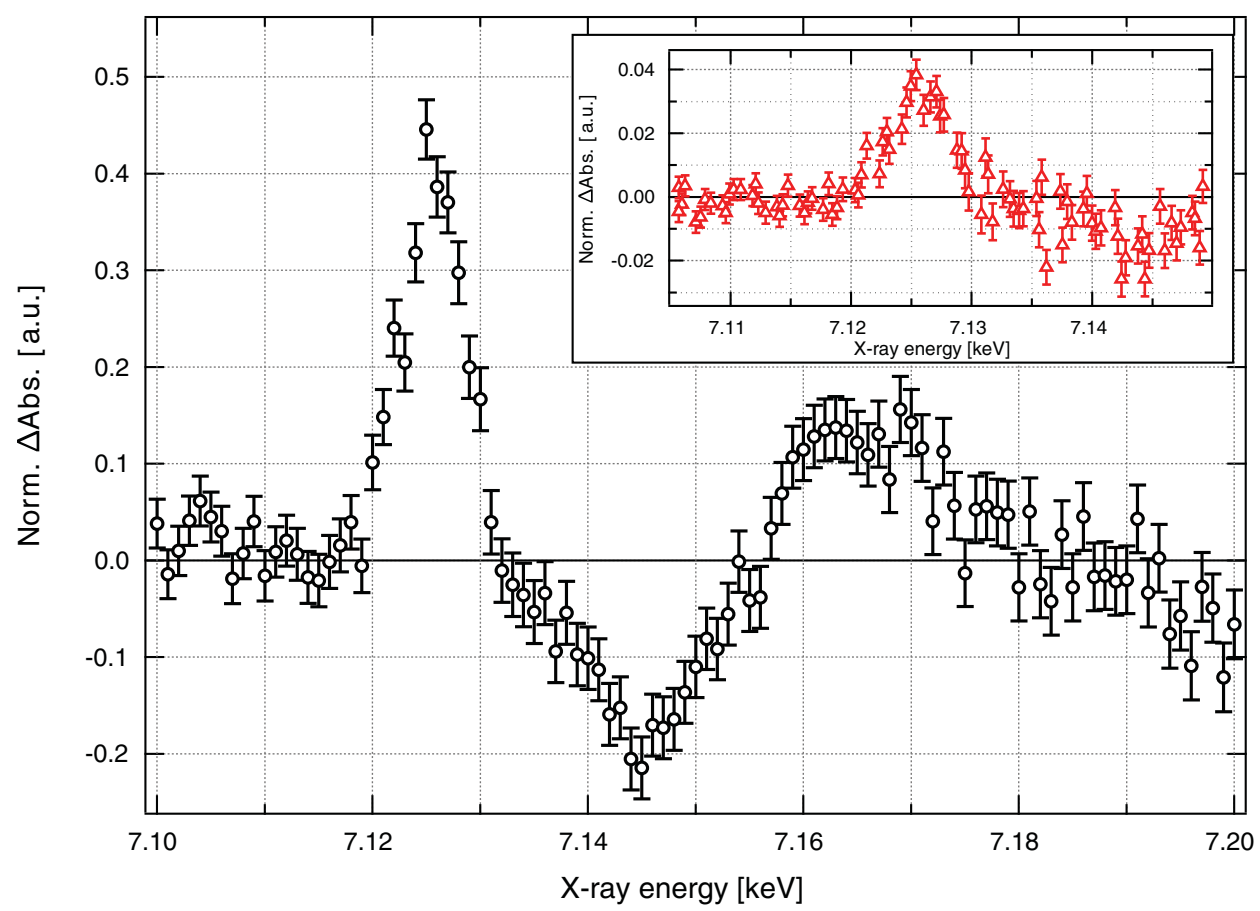

FIG. 8. (Color online) Average of 10 transient XAS scans $50 \mathrm{ps}$ after excitation, of a $1 \mathrm{mM}\left[\mathrm{Fe}(\mathrm{bpy})_{3}\right]^{2+}$ solution excited with a pump fluence of $150 \mathrm{~mJ} / \mathrm{cm}^{2}$. The inset shows a single transient XAS scan of a $25 \mathrm{mM}$ aqueous solution of $\left[\mathrm{Fe}(\mathrm{bpy})_{3}\right]^{2+}$ at $50 \mathrm{ps}$ delay and collected in fluorescence yield mode with a pump fluence of $13 \mathrm{~mJ} / \mathrm{cm}^{2}$.

for the $25 \mathrm{mM}$ sample excited with $100 \mathrm{~mJ} / \mathrm{cm}^{2}$. When using a laser fluence of $200 \mathrm{~mJ} / \mathrm{cm}^{2}$ the derived excitation yield increases to $80 \%-90 \%$. This value is over three times larger than the previously reported $22 \%$ achieved in the $\mathrm{kHz}$ experiments, ${ }^{20,43}$ and can be explained by the approximately three times larger optical absorption coefficient at $532 \mathrm{~nm}$ compared to at $400 \mathrm{~nm}$, and by the fact that the longer excitation pulse duration of $10 \mathrm{ps}$ compared to $100 \mathrm{fs}$ results in less nonlinear excitation of the solvent ${ }^{39}$ and more efficient excitation of the sample.

We can now attempt a more quantitative estimate of the gain in $\mathrm{S} / \mathrm{N}$ at $520 \mathrm{kHz}$ compared to $1 \mathrm{kHz}$. The $\mathrm{S} / \mathrm{N}$ is proportional to the excitation yield, the square root of the incoming $\mathrm{x}$-ray flux and the repetition rate of the laser. Therefore the gain in $\mathrm{S} / \mathrm{N}$ is given by the ratio:

$$
\frac{(\mathrm{S} / \mathrm{N})_{520 \mathrm{kHz}}}{(\mathrm{S} / \mathrm{N})_{1 \mathrm{kHz}}} \simeq \frac{70 \%}{22 \%} \sqrt{\frac{I_{\mathrm{x}-\mathrm{ray}}^{520 \mathrm{kHz}}}{I_{\mathrm{x} \text {-ray }}^{1 \mathrm{kHz}}}} \sqrt{\frac{520}{1}},
$$

where we have taken as average photolysis yield (70\%) from the above estimates. Estimating the difference in x-ray flux between the former $1 \mathrm{kHz}$ experiments and the present ones is not straightforward; however, we estimate an approximate factor of 8 decrease between the two experiments, due to differences in the beamline setup. ${ }^{46}$ Thus the factor of three higher photolysis yield is compensated for by the decrease in $\mathrm{x}$-ray flux. We conclude that the increase in S/N mainly scales with the square root of the increase in repetition rate.

Figure 6(b) shows a zoom of the pre-edge region. The black curve shows the ground-state pre-edge signal while the markers show the transient XAS measured using a fluence of
$200 \mathrm{~mJ} / \mathrm{cm}^{2}$. The pre-edge features correspond to the dipoleforbidden $1 \mathrm{~s} \rightarrow 3 \mathrm{~d}$ bound-bound transitions and are sensitive to the spin-state of the molecule. ${ }^{47}$ Since these features are less than $1 \%$ of the absorption edge jump, very high signal-tonoise is required to resolve them. ${ }^{48}$ As expected for an octahedrally coordinated low-spin $\mathrm{Fe}^{2+}$ metal center the groundstate shows a clear absorption peak corresponding to the $1 \mathrm{~s} \rightarrow$ $3 \mathrm{~d}\left(\mathrm{e}_{g}\right)$ transition $(7.1135 \mathrm{keV})$. Upon excitation to the highspin state, we see an increase in absorption at lower energies corresponding to the $1 \mathrm{~s} \rightarrow 3 \mathrm{~d}\left(\mathrm{t}_{2 g}\right)$ transition $(7.1125 \mathrm{keV})$ and a decrease at higher energies as the $3 \mathrm{~d}\left(\mathrm{e}_{g}\right)$ levels are populated in the high-spin state $(7.114 \mathrm{keV})$. There is also an increase in absorption at higher energies $(7.117 \mathrm{keV})$ in a region of the spectrum where peaks have been tentatively assigned to edge transitions. ${ }^{47}$ These pre-edge features were also seen by Nozawa et al. using kHz laser excitation ${ }^{48}$ but the increased $\mathrm{S} / \mathrm{N}$ in the present experiments allow us to perform a line shape analysis which will be presented in a forthcoming publication.

Given the gain in $\mathrm{S} / \mathrm{N}$, we can now decrease the sample concentration and/or the laser excitation fluence. Figure 8 shows the average of 10 individual scans of the transient XAS measured in FY mode of a $1 \mathrm{mM}$ solution of aqueous $\left[\mathrm{Fe}(\mathrm{bpy})_{3}\right]^{2+}$. This measurement was taken with a fluence of $150 \mathrm{~mJ} / \mathrm{cm}^{2}$ and both transmission and FY data were recorded simultaneously at $50 \mathrm{ps}$ after excitation. The total acquisition time for the data shown was about $1 \mathrm{~h}$, yielding $\mathrm{S} / \mathrm{N} \simeq 4.6$ per scan in fluorescence and $\mathrm{S} / \mathrm{N} \simeq 3$ in transmission. The inset to Fig. 8 shows the transient XAS signal in $\mathrm{FY}$ mode of a $25 \mathrm{mM}$ solution of aqueous $\left[\mathrm{Fe}(\mathrm{bpy})_{3}\right]^{2+}$, again at $50 \mathrm{ps}$ time delay, but excited with only $13 \mathrm{~mJ} / \mathrm{cm}^{2}$. 
In the limit of low laser fluence, we are still able to measure a time-resolved signal with a $\mathrm{S} / \mathrm{N} \simeq 8$ in a single scan. The results of Fig. 8 show that we can now measure very dilute or photochemically unstable samples within reasonable data acquisition times, opening the way for the investigation of biological samples under physiological conditions.

\section{B. Ruthenium tris-bipyridine}

One of the advantages of the high-repetition rate setup is its portability. The tender $\mathrm{x}$-ray beamline PHOENIX I has recently come online at the SLS enabling us to measure core transitions of species not covered by the hard x-ray microXAS beamline. In order to ascertain the feasibility of such low x-ray energy measurements we chose to investigate $\left[\mathrm{Ru}(\mathrm{bpy})_{3}\right]^{2+}$ which we previously characterized by ps XAS at the Advanced Light Source (ALS, Berkeley, USA). ${ }^{16,49}$ Ruthenium tris-bipyridine is a model system for intramolecular electron transfer reactions and is representative of a large class of compounds for applications in solar energy conversion. Upon visible-UV excitation at either 355 or $532 \mathrm{~nm}$, one reaches the ${ }^{1}$ MLCT (metal-to-ligand-charge-transfer) state, which decays to the long-lived (several hundred ns in room temperature aqueous solutions ${ }^{50}$ ) ${ }^{3}$ MLCT state on ultrafast timescales. ${ }^{34}$ The lifetime of the ${ }^{3}$ MLCT state can be reduced by the presence of oxygen in the solvent. ${ }^{38}$ In the MLCT state the electron is localized on one of the bipyridine ligands: $\left[\mathrm{Ru}^{\mathrm{III}}\left(\mathrm{bpy}^{-}\right)(\mathrm{bpy})_{2}\right]^{2+} \cdot{ }^{21}$ Exciting at $532 \mathrm{~nm}$ reaches the red wing of the absorption, but it has the advantage of not being reabsorbed by the ${ }^{3}$ MLCT state. ${ }^{50}$ Exciting at $355 \mathrm{~nm}$ has the advantage of a larger absorption cross section, resulting in a higher excitation probability, but there is a strong ligand-centered excited state absorption at $355 \mathrm{~nm}$ in the ${ }^{3}$ MLCT which may result in sequential two-photon absorption. The lifetime of this state is $<10 \mathrm{ps,}$ meaning we are not probing it at $50 \mathrm{ps}$, but the potential exists for other excited photoproducts to occur, including both $\left[\mathrm{Ru}(\mathrm{bpy})_{3}\right]^{+}$and $\left[\mathrm{Ru}(\mathrm{bpy})_{3}\right]^{3+} \cdot{ }^{50}$ By probing the system at the $\mathrm{Ru} \mathrm{L} \mathrm{L}_{2,3}$ edges (2.8-3 keV) in picosecond experiments at $1 \mathrm{kHz}$, an oxidation state-induced change in the ionization potential of $1.8 \mathrm{eV}$ was detected and a $\mathrm{Ru}-\mathrm{N}$ bond contraction of $\sim 0.03 \AA$ was derived. ${ }^{49,52}$

Excitation of an $80 \mathrm{mM}$ sample of $\left[\mathrm{Ru}(\mathrm{bpy})_{3}\right]^{2+}$ at $532 \mathrm{~nm}$ with a fluence of $115 \mathrm{~mJ} / \mathrm{cm}^{2}$ yield the twodimensional time-energy plot of Fig. 9. The data were collected as monochromator energy scans around the $\mathrm{Ru}-\mathrm{L}_{3}$ edge and taken with time steps of 12 ns out to 200 ns after excitation. Each energy scan represents the average of 4 individual scans and the total data acquisition time required was 2 h. From Fig. 9 it is clear that, within the signal-tonoise, the transient difference signal appears to simply decay in amplitude with no energy shifts over the course of its relaxation, confirming that we are probing the lifetime of the ${ }^{3}$ MLCT state. Neither the ground-state XAS nor the transient indicate the presence of any photoproducts, permanent or photoexcited, other than the expected $\left[\mathrm{Ru}^{\mathrm{III}}\left(\mathrm{bpy}{ }^{-}\right)(\mathrm{bpy})_{2}\right]^{2+}$. The timescale of the excited-state relaxation is $107 \pm 16 \mathrm{~ns}$, typical of a high-concentration solution with oxygen
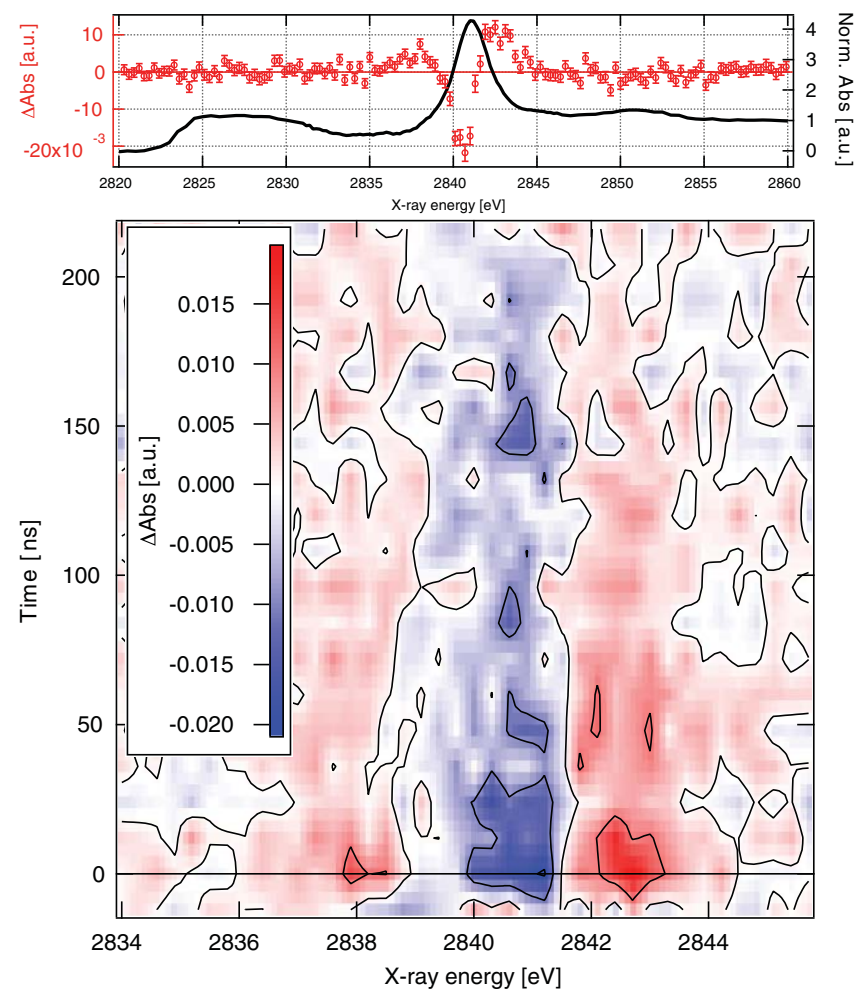

FIG. 9. (Color online) Top: Comparison between the ground-state XAS (black line) and transient XAS (red circles) measured 175 ps after time zero at the $\mathrm{Ru} \mathrm{L}_{3}$ edge of an $80 \mathrm{mM}$ solution of $\left[\mathrm{Ru}(\mathrm{bpy})_{3}\right]^{2+}$ excited at $532 \mathrm{~nm}$ with a fluence of $115 \mathrm{~mJ} / \mathrm{cm}^{2}$. Note that the pre-edge signal on the ground-state XAS, from 2825 to $2830 \mathrm{eV}$, is the $\mathrm{Cl} \mathrm{K}$-edge absorption of the counter-ion. Bottom: Two-dimensional time-energy XAS measured under the same conditions.

content. ${ }^{38}$ Figure 10 shows a transient energy scan comparing excitation at $532(\Delta t=175 \mathrm{ps}$, average of 8 scans $)$ and $355 \mathrm{~nm}(\Delta t=5.6 \mathrm{~ns}$, average of 6 scans $)$. Both signals show the expected decrease/increase in absorption at $2841 / 2843 \mathrm{eV}$ due to oxidation of the $\mathrm{Ru}$ atom from $2+$ to $3+$. The absorption increase at $2838 \mathrm{eV}$ is due to the creation of a hole in the $\mathrm{Ru} \mathrm{d}\left(\mathrm{t}_{2 g}\right)$ orbital, which can be accessed from the $2 \mathrm{p}_{3 / 2}$ core orbital when an electron is transferred to the ligand. ${ }^{16,18,49}$ The fluence at $532 \mathrm{~nm}$ was $115 \mathrm{~mJ} / \mathrm{cm}^{2}$ while for $355 \mathrm{~nm}$ it was $86 \mathrm{~mJ} / \mathrm{cm}^{2}$. The differential absorption change is similar for the two signals. The absorption cross section at $532 \mathrm{~nm}$ is approximately 3-4 times lower than that at $355 \mathrm{~nm}$, however due to the high concentration of the sample (80 mM) the optical density of the $100 \mu \mathrm{m}$ jet is around 1 for $532 \mathrm{~nm}$.

These proof-of-principle results illustrate the portability of the high-repetition rate system over the amplified $\mathrm{kHz}$ system. The primary challenge to moving to lower $\mathrm{x}$-ray energies is the loss of photons to solvent scattering and absorption. The $\mathrm{X}$-ray transmission through a $100 \mu \mathrm{m}$ jet of pure water is less than $15 \%$ at photon energies below $3 \mathrm{keV}$, making absorption experiments increasingly difficult. Clearly the ability to take data at $\mathrm{MHz}$ repetition rates is a distinct advantage for this energy range as the faster data acquisition in part compensates for the loss in $\mathrm{x}$-ray flux. 


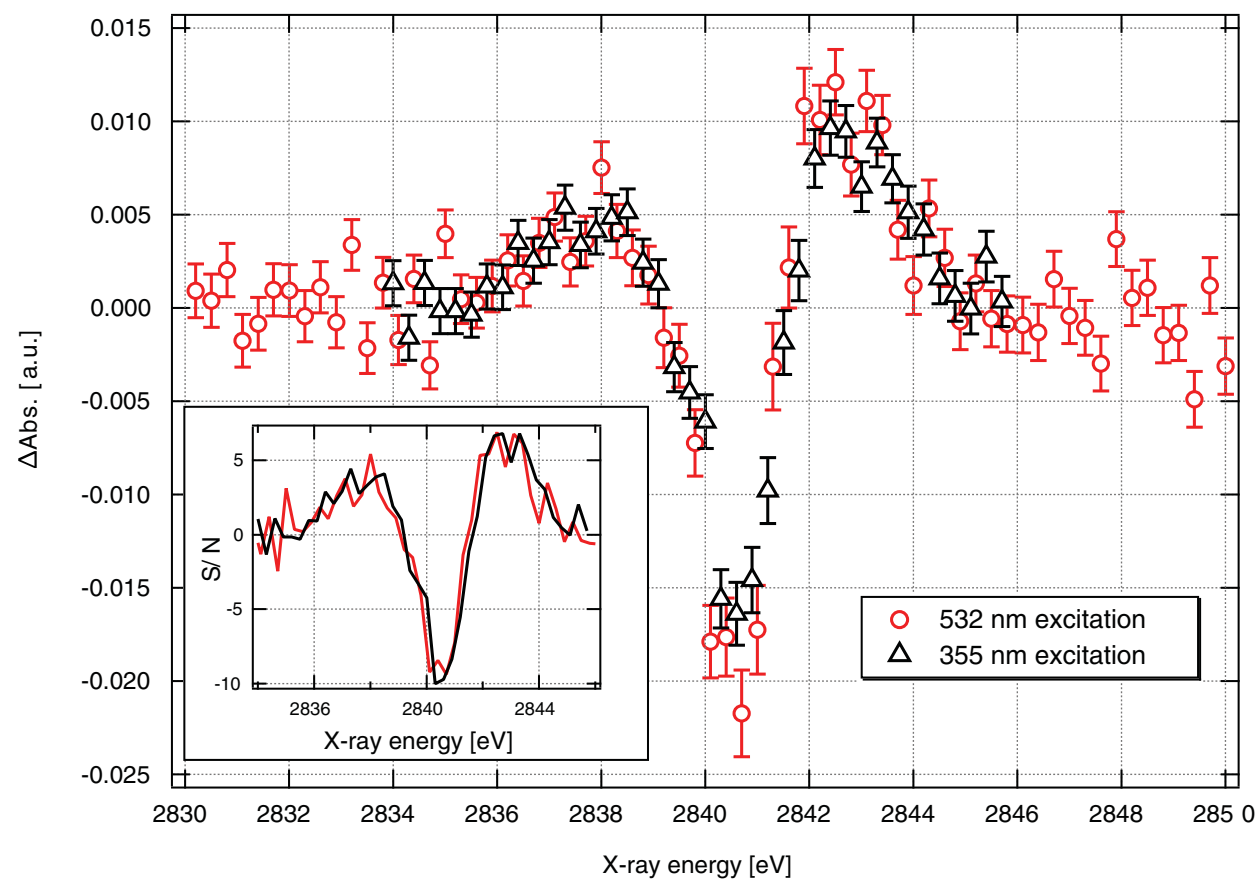

FIG. 10. (Color online) Comparison of the transient transmission XAS of an $80 \mathrm{mM}$ aqueous solution of $\left[\mathrm{Ru}(\mathrm{bpy})_{3}\right]^{2+}$ for excitation at $355 \mathrm{~nm} / \Delta t=5.6 \mathrm{~ns}$ (black triangles) and $532 \mathrm{~nm} / \Delta \mathrm{t}=175 \mathrm{ps}$ (red circles). The inset shows the $\mathrm{S} / \mathrm{N}$ of the data with the $355 \mathrm{~nm}$ data being an average of 6 scans and the $532 \mathrm{~nm}$ data an average of 8 scans.

\section{Carboxymyoglobin}

The ability to acquire time-resolved XAS data of highly dilute samples with reasonable signal-to-noise is crucial for the study of biological samples. Myoglobin (Mb), whose main function is to facilitate oxygen diffusion in mammal muscle cells, is one of the most studied metalloproteins. Its active center consists of a porphyrin ring with an iron atom in the center (the metalloporphyrin), to which small diatomic molecular ligands such as $\mathrm{O}_{2}, \mathrm{CO}, \mathrm{NO}$ and $\mathrm{CN}$ can bind. The ligand dissociation can be triggered by irradiation with visible light and the recombination dynamics has led to innumerable studies using a broad range of timeresolved optical techniques. ${ }^{53,54}$ In the case of carboxymyoglobin (MbCO), the recombination occurs in microseconds to milliseconds. ${ }^{55-57}$ It was first investigated by time-resolved XAS with $\mu$ s resolution by Mills et al. ${ }^{58}$ who developed a scheme using a synchronized Nd:YAG laser to photolyze the $\mathrm{MbCO}$ in a flowing sample solution and probed around the Fe K-shell XANES region (7 keV). Several early XAS measurements also used cryogenic temperatures to lengthen the $\mathrm{CO}$ rebinding time in solid samples with photolysis triggered using flashlamp illumination. ${ }^{59-61}$ Later, Clozza et al. ${ }^{62}$ developed an apparatus that used the synchrotron as a quasicontinuous source where the data acquisition was triggered by the laser making it possible to make FY measurements at well-defined time delays using time-windows down to the millisecond time scale. Several years later Chance et al. took advantage of advances in energy-resolving x-ray fluorescence detectors to perform measurements on $\mathrm{MbCO}$ using both laser ${ }^{63}$ and flashlamp excitation ${ }^{64}$ allowing them to collect time-resolved XAS spectra in the several microseconds to milliseconds time domain for dilute cryogenic sam- ples (1-4 mM). More recently Arcovito, Della Longa and coworkers have used myoglobin single crystals to perform polarized XAS measurements to collect data both parallel and perpendicular to the heme normal which has allowed them to see pronounced changes after photolysis in the $\mathrm{Fe}-\mathrm{CO}$ bond direction. ${ }^{65-67}$ They have also investigated the temperaturedependence of the CO-rebinding rate ${ }^{68}$ and showed that it is possible to photo-reduce the $\mathrm{Fe}$ center with x-rays, ${ }^{69} \mathrm{em}$ phasizing the potential for sample damage through $\mathrm{x}$-ray exposure. Concurrent with these experimental advances, analysis tools have also matured, making it possible to extract more detailed structural information from both the XANES (Refs. 67 and 70) and EXAFS (Ref. 64) regions of the spectrum. It should be stressed that the majority of these measurements concerned cryogenically cooled solid samples, therefore far from physiological conditions.

Recording the time-resolved XAS experiments at high repetition rates using the pulse-to-pulse data acquisition is not convenient for systems whose ground-state recovery is longer than the pulse repetition period. This is the case with $\mathrm{MbCO}$ which has a ligand recombination time of milliseconds. ${ }^{56} \mathrm{Re}-$ ducing the repetition rate of the laser so that the sample can relax between $\mathrm{x}$-ray probe pulses cancels the advantages of the high repetition rate. An alternative approach would be to measure data at fixed (e.g. $1 \mathrm{~s}$ ) alternating intervals for the laser-excited and the unexcited XAS. The unpumped measurement is achieved by moving the laser position horizontally with a motorized laser mirror to ensure a complete lack of laser/x-ray overlap. The differential absorption, or slowdifference transient, can then be calculated using these data. The transient XAS signals are still calculated as in Eqs (1) and (2), the difference being that now the pumped signal is 

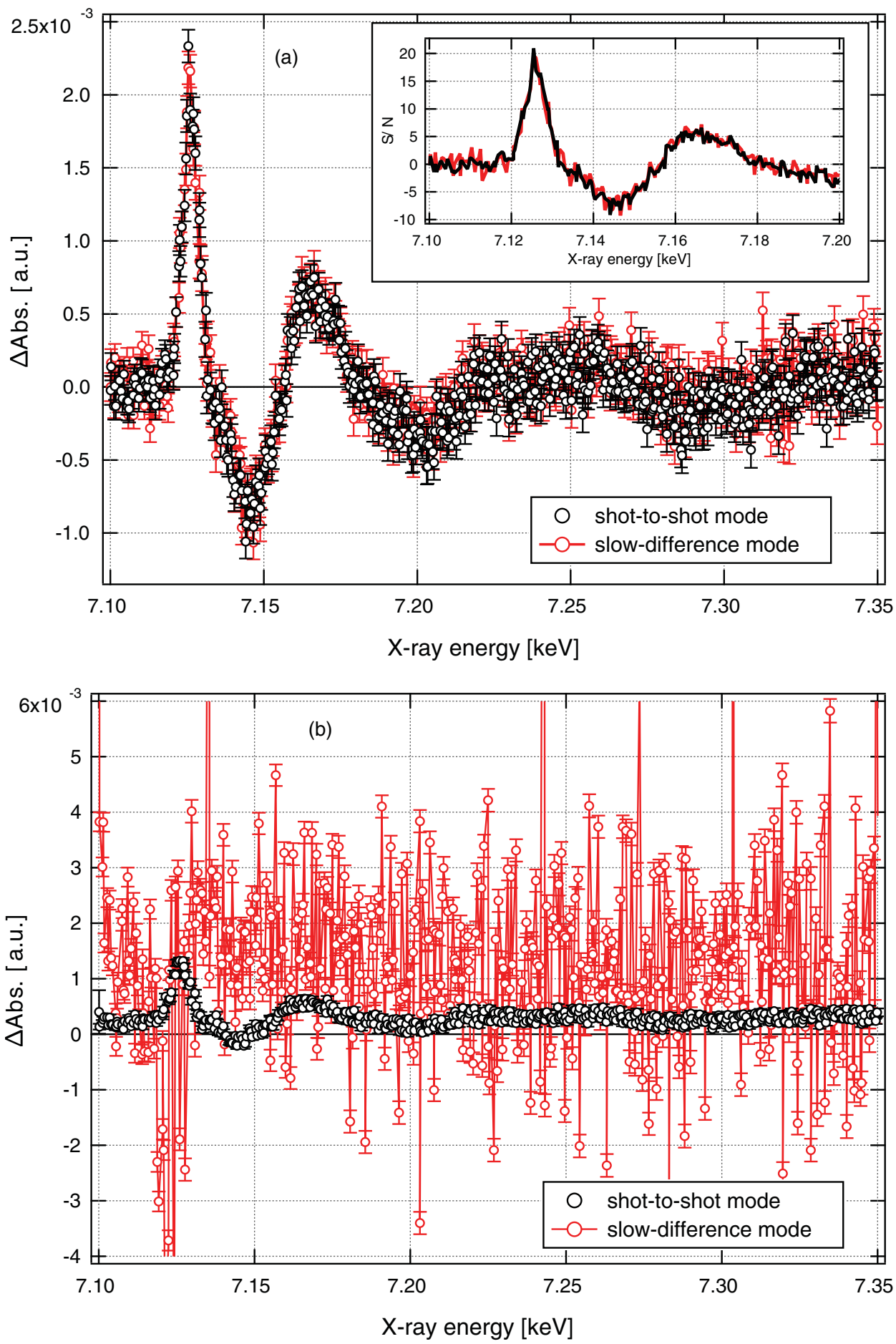

FIG. 11. (Color online) Comparison of the transient XAS signal of a single measurement of a $7 \mathrm{mM}$ aqueous solution of $\left[\mathrm{Fe}(\mathrm{bpy})_{3}\right]^{2+}$ excited with $150 \mathrm{~mJ} / \mathrm{cm}^{2}$ laser fluence, using the pulse-to-pulse and the slow-difference modes in fluorescence (a) and transmission (b). Black circles show the data collected using the pulse-to-pulse mode and the red circles show the data collected using the slow-difference mode. Note that both measurement modes have the same $\mathrm{S} / \mathrm{N}$ for fluorescence (see inset on (a)) while being drastically different in transmission.

defined as the signal measured when the laser and x-rays are overlapped spatially and unpumped is the signal with no overlap.

Using this alternative scan technique, other sources of noise can contribute to the measured signal since the differential absorption is now being calculated on a $1 \mathrm{~s}$ timescale as opposed to a $1 \mu$ s timescale. In order to investigate the noise characteristics of this slow-difference technique, we recorded a set of transient energy spectra of a sample of $7 \mathrm{mM}$ aqueous $\left[\mathrm{Fe}(\mathrm{bpy})_{3}\right]^{2+}$ at $50 \mathrm{ps}$ time delay using simultaneously both the regular (pulse-to-pulse) and slow-difference scan modes, enabling a direct comparison of both scan modes under identical experimental conditions.

The transient XAS data collected in fluorescence and transmission using both modes is shown in Fig. 11. A comparison of the transient XAS data recorded in FY mode 


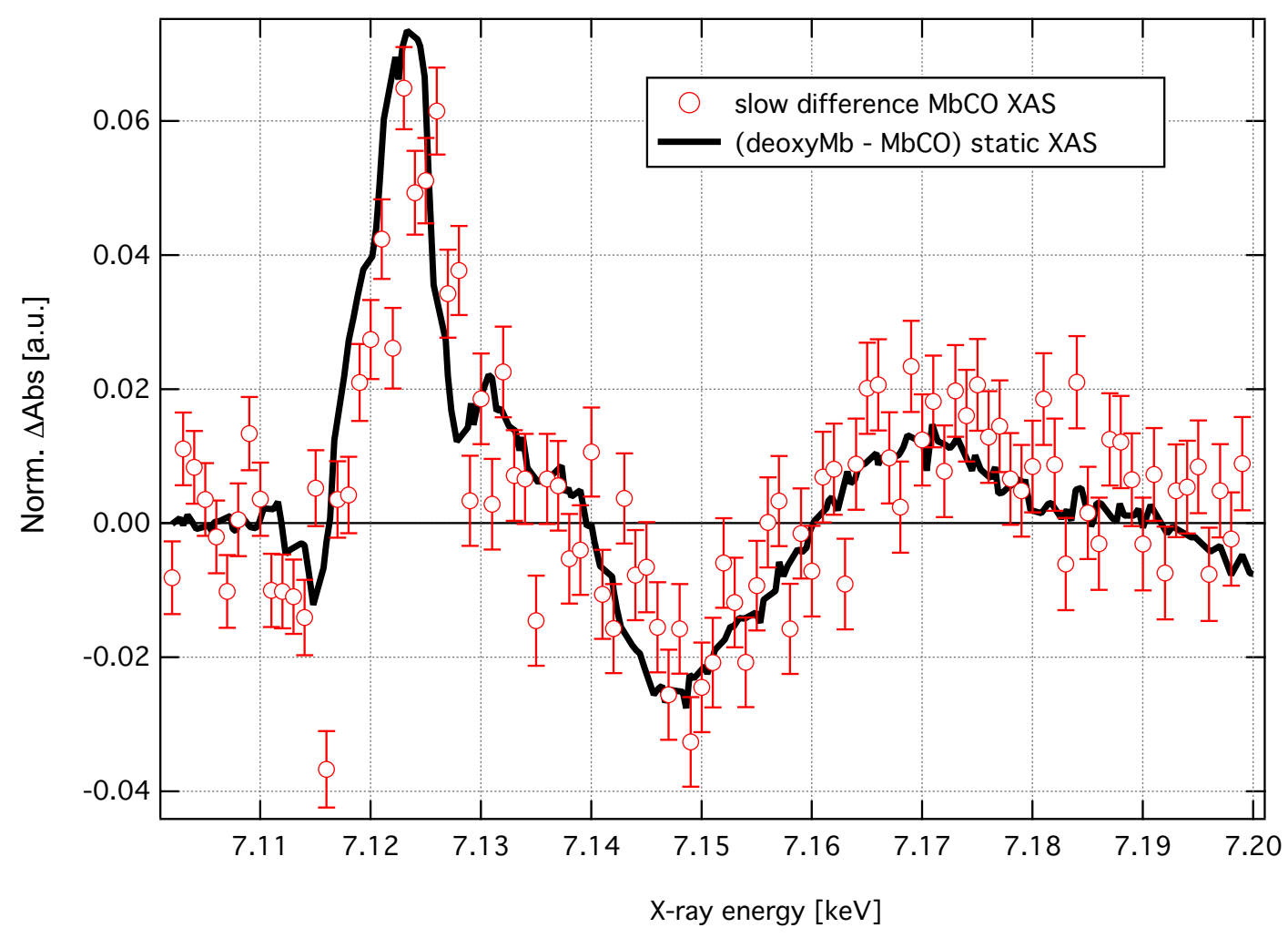

FIG. 12. (Color online) Transient XAS of $2 \mathrm{mM} \mathrm{MbCO}$ collected in fluorescence yield mode. The sample was excited at $125 \mathrm{~mJ} / \mathrm{cm}^{2}$ laser fluence. The black curve represents the difference XAS based on the static spectra of deoxyMb and MbCO assuming an excitation yield of $21 \%$.

using both data acquisition modes show no new sources of noise that can obscure the signal in the slow-difference mode. The $\mathrm{S} / \mathrm{N}$ of both data sets (see inset in Fig. 11 (a)) is almost identical from which we conclude that in the case of samples having long-lived excited states, we can use the slowdifference scan mode in fluorescence to collect transient XAS data while only incurring a factor of two penalty in data acquisition times. The comparison of the two scan modes in transmission is shown in Fig. 11 (b). The transmission signal recorded using the slow-difference scan reveals an enormous source of noise which obscures the signal, in stark contrast to the pulse-to-pulse mode. This indicates that there is an external source of noise on the $1 \mathrm{~s}$ time scale, which is absent on the $1 \mu \mathrm{s} \mathrm{timescale,} \mathrm{and} \mathrm{is} \mathrm{most} \mathrm{probably} \mathrm{due} \mathrm{to} \mathrm{the} \mathrm{flow} \mathrm{of} \mathrm{the}$ liquid sample. Indeed small fluctuations in the jet flow speed, pressure and thickness easily introduce changes in the $\mathrm{x}$-ray absorption signal on the $1 \mathrm{~s}$ timescale resulting in large random changes in the differential absorption. This noise easily overwhelms the transient transmission signal and reinforces the importance of measuring the difference signals on a pulseto-pulse basis. For the study of dilute samples it is preferable to use FY detection.

The averaged transient FY XAS signal of photo-excited $\mathrm{MbCO}$ is shown in Fig. 12. It consists of 32 individual scans and a data collection time of $4.5 \mathrm{~h}$, and was measured using the slow-difference scan mode, with a laser fluence of $125 \mathrm{~mJ} / \mathrm{cm}^{2}$. It exhibits several pronounced changes in the XANES region of the spectrum, with the largest change in absorption at $7.123 \mathrm{keV}$ being due to a shift to lower-energy of the Fe absorption edge. This transient represents the difference in XAS spectra of the ligated minus the unligated protein. We measured the static XAS spectra of the CO-ligated form of myoglobin ( $\mathrm{MbCO}$ ), the unligated form of myoglobin (deoxyMb), and the unreduced form of myoglobin (metMb), as reference. After ligand photo-detachment and in the absence of any intermediate structure on the time scale of the measurement, we expect the spectrum of the photo-product to resemble that of deoxyMb. The transient spectrum should then be similar to the difference spectrum of the deoxy form minus the ligated form. This difference spectrum represents a limiting case in which all the ligands are photo-detached and no intermediate structure is present. This is a good approximation for $\mathrm{MbCO}$ where there is almost no geminate recombination $^{55,56}$ and no evidence of any partially bound structural intermediates. ${ }^{5}$ A scale factor can therefore be used when comparing it to the measured transient XAS, allowing us to estimate the fraction of excited species. Overlaid on the experimental transient XAS is the difference of the deoxy static spectrum minus the MbCO static spectrum which has been scaled by a factor of 0.21 for comparison, implying an excitation yield of $\sim 21 \%$. Because the measurements were done using the slow-difference scan mode, the time delay is not well defined. Since the time interval between consecutive laser pump pulses at $520 \mathrm{kHz}$ is $2 \mu$ s, the excitedstate population is an ensemble composed of the population at $50 \mathrm{ps}$, which is the time delay set between the pump and probe pulses, and $2 \mu \mathrm{s}$, which is the time interval between two consecutive laser pulses. In essence every laser pump pulse 
excites a sample which is only partially relaxed, leading to a larger average population of deoxyMb than would exist after a single excitation pulse.

Comparing the measured transient signal with the predicted difference based on the static XAS, one can see that within the error bars, both signals coincide. A more detailed discussion of these results will be presented in a forthcoming publication.

\section{CONCLUSION AND OUTLOOK}

We have developed a flexible setup for $\mathrm{x}$-ray absorption spectroscopy with $<100$ ps temporal resolution at $\mathrm{MHz}$ data acquisition rates. Our configuration makes use of all the available isolated x-ray pulses from the hybrid filling mode currently employed at most third-generation synchrotrons. This allows the measurement of laser-induced changes on the $\mathrm{x}$ ray absorption spectra of dilute samples with concentrations of the order of a mM. We demonstrate the ability of the setup to perform shot noise limited measurements with an increase in $\mathrm{S} / \mathrm{N}$ of the order of $\simeq \sqrt{f_{L}}$ where $f_{L}$ is the repetition rate of the laser pump (520 kHz), compared to the $1 \mathrm{kHz}$ data acquisition techniques. The portability of the setup has also been demonstrated on a tender $x$-ray beamline. As a final test of the high-repetition rate data acquisition technique we also measured the differential XAS of a dilute solution of carboxymyoglobin.

The temporal resolution is limited at present by the duration of the synchrotron $\mathrm{x}$-ray pulses. This can be improved to a few picoseconds using the so-called "low-alpha" mode ${ }^{71-73}$ available at several third-generation synchrotron sources. The moderate decrease in $\mathrm{x}$-ray flux is compensated for by the higher repetition rate, providing intermediate temporal resolution between the hundreds of ps obtained directly from synchrotrons and hundreds of fs from the electron-laser slicing scheme. ${ }^{74}$ Finally, the simplicity of the present scheme means that it can be implemented at any synchrotron beamline, and extended to any time-resolved $\mathrm{x}$-ray technique (absorption, emission, or diffraction).

\section{ACKNOWLEDGMENTS}

We thank Dr. Gaudenz Jud, Mr. A. Oggenfuss, Mr. Beat Meyer, and Mr. R. Wetter for their assistance during this project and Drs. W. Gawelda and M. Johnson for fruitful discussions. This work was financed by the FNS via Contract Nos. 200020-12723, 200021-116394, and 206021-117401 and the NCCR MUST.

${ }^{1}$ M. Chergui and A. H. Zewail, ChemPhysChem 10, 28 (2009).

${ }^{2}$ S. L. Johnson, P. Beaud, E. Vorobeva, C. J. Milne, E. D. Murray, S. Fahy, and G. Ingold, Acta Crystallogr. A 66, 157 (2010).

${ }^{3}$ T. Elsaesser and M. Woerner, Acta Crystallogr. A 66, 168 (2010).

${ }^{4}$ P. Beaud, S. L. Johnson, E. Vorobeva, U. Staub, R. A.D. Souza, C. J. Milne, Q. X. Jia, and G. Ingold, Phys. Rev. Lett. 103, 155702 (2009).

${ }^{5}$ F. Schotte, M. Lim, T. Jackson, A. Smirnov, J. Soman, J. Olson, G. Phillips, M. Wulff, and P. A. Anfinrud, Science 300, 1944 (2003).

${ }^{6}$ S. Bratos and M. Wulff, Adv. Chem. Phys. 137, 1 (2008).

${ }^{7}$ T. K. Kim, J. H. Lee, M. Wulff, Q. Kong, and H. Ihee, ChemPhysChem 10, 1958 (2009).

${ }^{8}$ C. Bressler and M. Chergui, Chem. Rev. 104, 1781 (2004).
${ }^{9}$ L. Chen, Angew. Chem., Int. Ed. 43, 2886 (2004).

${ }^{10}$ L. X. Chen, X. Zhang, J. V. Lockard, A. B. Stickrath, K. Attenkofer, G. Jennings, and D.-J. Liu, Acta Crystallogr. A 66, 240 (2010).

${ }^{11}$ C. Bressler, R. Abela, and M. Chergui, Z Kristallogr. 223, 307 (2008).

${ }^{12}$ C. Bressler and M. Chergui, Annu. Rev. Phys. Chem. 61, 263 (2010).

${ }^{13}$ M. Chergui, Acta Crystallogr. A 66, 229 (2010).

${ }^{14}$ L. X. Chen, J. Electron Spectrosc. 119, 161 (2001).

${ }^{15}$ L. X. Chen, G. Jennings, T. Liu, D. Gosztola, J. Hessler, D. Scaltrito, and G. Meyer, J. Am. Chem. Soc. 124, 10861 (2002).

${ }^{16}$ M. Saes, C. Bressler, R. Abela, D. Grolimund, S. L. Johnson, P. A. Heimann, and M. Chergui, Phys. Rev. Lett. 90, 047403 (2003).

${ }^{17}$ M. Saes, F. van Mourik, W. Gawelda, M. Kaiser, M. Chergui, C. Bressler, D. Grolimund, R. Abela, T. E. Glover, P. A. Heimann, R. W. Schoenlein, S. L. Johnson, A. M. Lindenberg, and R. W. Falcone, Rev. Sci. Instrum. 75, 24 (2004).

${ }^{18}$ W. Gawelda, C. Bressler, M. Saes, M. Kaiser, A. N. Tarnovsky, D. Grolimund, S. L. Johnson, R. Abela, and M. Chergui, Phys. Scr. T115, 102 (2005).

${ }^{19}$ M. Khalil, M. A. Marcus, A. L. Smeigh, J. K. McCusker, H. H.W. Chong, and R. W. Schoenlein, J. Phys. Chem. A 110, 38 (2006).

${ }^{20}$ W. Gawelda, V.-T. Pham, M. Benfatto, Y. Zaushitsyn, M. Kaiser, D. Grolimund, S. L. Johnson, R. Abela, A. Hauser, C. Bressler, and M. Chergui, Phys. Rev. Lett. 98, 4 (2007).

${ }^{21}$ V.-T. Pham, W. Gawelda, Y. Zaushitsyn, M. Kaiser, D. Grolimund, S. L. Johnson, R. Abela, C. Bressler, and M. Chergui, J. Am. Chem. Soc. 129, 1530 (2007).

${ }^{22}$ L. X. Chen, X. Zhang, E. C. Wasinger, K. Attenkofer, G. Jennings, A. Z. Muresan, and J. S. Lindsey, J. Am. Chem. Soc. 129, 9616 (2007).

${ }^{23}$ C. G. Elles, I. A. Shkrob, R. A. Crowell, D. A. Arms, and E. C. Landahl, J. Chem. Phys. 128, 061102 (2008)

${ }^{24}$ R. M. van der Veen, C. J. Milne, A. E. Nahhas, F. Lima, V.-T. Pham, J. Best, J. A. Weinstein, C. N. Borca, R. Abela, C. Bressler, and M. Chergui, Angew. Chem., Int. Ed. 48, 2711 (2009).

${ }^{25}$ N. Huse, H. Wen, D. Nordlund, E. Szilagyi, D. Daranciang, T. A. Miller, A. Nilsson, R. W. Schoenlein, and A. M. Lindenberg, Phys. Chem. Chem. Phys. 11, 3951 (2009).

${ }^{26}$ H. Wen, N. Huse, R. W. Schoenlein, and A. M. Lindenberg, J. Chem. Phys. 131, 234505 (2009).

${ }^{27}$ N. Huse, T. K. Kim, L. Jamula, J. K. McCusker, F. M.F. de Groot, and R. W. Schoenlein, J. Am. Chem. Soc. 132, 6809 (2010).

${ }^{28}$ N. Huse, H. Cho, K. Hong, L. Jamula, F. M.F. de Groot, T. K. Kim, J. K. McCusker, and R. W. Schoenlein, J. Phys. Chem. Lett. 2, 880 (2011).

${ }^{29}$ W. Widdra, D. Brocker, T. Giessel, I. Hertel, W. Kruger, A. Liero, F. Noack, V. Petrov, D. Pop, P. Schmidt, R. Weber, I. Will, and B. Winter, Surf. Sci. 543, 87 (2003).

${ }^{30}$ T. Giessel, D. Brocker, P. Schmidt, and W. Widdra, Rev. Sci. Instrum. 74, 4620 (2003).

${ }^{31}$ E. Stern and D. Brewe, AIP Conf. Proc. 882, 24 (2007).

${ }^{32}$ D. Brewe, S. Heald, E. Stern, K. Beck, and Y. Feng, AIP Conf. Proc. 705, 1399 (2004)

${ }^{33}$ A. Cannizzo, C. J. Milne, C. Consani, W. Gawelda, C. Bressler, F. van Mourik, and M. Chergui, Coord. Chem. Rev. 254, 2677 (2009).

${ }^{34}$ A. Cannizzo, F. van Mourik, W. Gawelda, G. Zgrablic, C. Bressler, and M. Chergui, Angew. Chem. Int. Ed. 45, 3174 (2006).

${ }^{35}$ P. Beaud, S. L. Johnson, A. Streun, R. Abela, D. Abramsohn, D. Grolimund, F. S. Krasniqi, T. Schmidt, V. Schlott, and G. Ingold, Phys. Rev. Lett. 99, 174801 (2007).

${ }^{36} \mathrm{C}$. Borca, D. Grolimund, M. Willimann, B. Meyer, K. Jefimovs, J. Comamala, and C. David, J. Phys.: Conf. Ser. 186, 012003 (2009).

${ }^{37}$ C. Bressler, M. Saes, M. Chergui, D. Grolimund, R. Abela, and P. Pattison, J. Chem. Phys. 116, 2955 (2002).

${ }^{38} \mathrm{M}$. Saes, Picosecond X-ray absorption spectroscopy: application to coordination chemistry compounds in solution, Ph.D. thesis, (Ecole Polytechnique Fédérale de Lausanne, 2004).

${ }^{39} \mathrm{~W}$. Gawelda, Time-resolved $\mathrm{x}$-ray absorption spectroscopy of transition metal complexes, Ph.D. thesis, (Ecole Polytechnique Fédérale de Lausanne, 2006).

${ }^{40}$ E. Antonini and M. Brunori, Hemoglobin and Myoglobin in Their Reactions With Ligands, edited by N.-H. P. Company (North-Holland:London, 1971).

${ }^{41}$ M. Lim, T. Jackson, and P. A. Anfinrud, J. Am. Chem. Soc. 126, 7946 (2004). 
${ }^{42}$ W. Gawelda, A. Cannizzo, V.-T. Pham, F. van Mourik, C. Bressler, and M. Chergui, J. Am. Chem. Soc. 129, 8199 (2007).

${ }^{43}$ W. Gawelda, V.-T. Pham, R. M. van der Veen, D. Grolimund, R. Abela, M. Chergui, and C. Bressler, J. Chem. Phys. 130, 124520 (2009).

${ }^{44}$ C. Bressler, C. J. Milne, V.-T. Pham, A. E. Nahhas, R. M. van der Veen, W. Gawelda, S. L. Johnson, P. Beaud, D. Grolimund, M. Kaiser, C. N. Borca, G. Ingold, R. Abela, and M. Chergui, Science 323, 489 (2009).

${ }^{45}$ C. Consani, M. Prémont-Schwarz, A. E. Nahhas, C. Bressler, F. van Mourik, A. Cannizzo, and M. Chergui, Angew. Chem., Int. Ed. 48, 7184 (2009).

${ }^{46} \mathrm{~A}$ factor of two from tighter $\mathrm{x}$-ray focussing, a factor of two from monochromator changes and a factor of two from the air path.

${ }^{47}$ T. Westre, P. Kennepohl, J. DeWitt, B. Hedman, K. Hodgson, and E. Solomon, J. Am. Chem. Soc. 119, 6297 (1997).

${ }^{48}$ S. Nozawa, T. Sato, M. Chollet, K. Ichiyanagi, A. Tomita, H. Fujii, S.-i. Adachi, and S. ya Koshihara, J. Am. Chem. Soc. 132, 61 (2010).

${ }^{49}$ W. Gawelda, M. Johnson, F. M.F. de Groot, R. Abela, C. Bressler, and M. Chergui, J. Am. Chem. Soc. 128, 5001 (2006).

${ }^{50}$ A. N. Tarnovsky, W. Gawelda, M. Johnson, C. Bressler, and M. Chergui, J. Phys. Chem. B 110, 26497 (2006).

${ }^{51}$ M.-E. Moret, I. Tavernelli, M. Chergui, and U. Rothlisberger, Chem. Eur. J. 16, 5889 (2010).

${ }^{52}$ M. Benfatto, S. D. Longa, K. Hatada, K. Hayakawa, W. Gawelda, C. Bressler, and M. Chergui, J. Phys. Chem. B 110, 14035 (2006).

${ }^{53}$ J. Martin and M. H. Vos, Annu. Rev. Biophys. Biomol. 21, 199 (1992).

${ }^{54}$ M. H. Vos, Bba-Bioenergetics 1777, 15 (2008).

${ }^{55}$ E. Henry, J. Sommer, J. Hofrichter, and W. Eaton, J. Mol. Biol. 166, 443 (1983).

${ }^{56}$ W. Tian, J. Sage, V. Srajer, and P. Champion, Phys. Rev. Lett. 68, 408 (1992).

${ }^{57}$ M. Walther, V. Raicu, J. Ogilvie, R. Phillips, R. Kluger, and R. J. D. Miller, J. Phys. Chem. B 109, 20605 (2005).

${ }^{58}$ D. M. Mills, A. Lewis, A. Harootunian, J. Huang, and B. Smith, Science 223, 811 (1984).

${ }^{59}$ B. Chance, R. Fischetti, and L. Powers, Biochemistry 22, 3820 (1983).
${ }^{60}$ L. Powers, B. Chance, M. Chance, B. Campbell, J. Friedman, S. Khalid, C. Kumar, A. Naqui, K. Reddy, and Y. Zhou, Biochemistry-Us 26, 4785 (1987).

${ }^{61}$ T. Teng, H. Huang, and G. Olah, Biochemistry-Us 26, 8066 (1987).

${ }^{62}$ A. Clozza, A. Castellano, S. D. Longa, A. Giovannelli, and A. Bianconi, Rev. Sci. Instrum. 60, 2519 (1989).

${ }^{63}$ M. Chance, M. Wirt, E. Scheuring, L. Miller, A. Xie, and D. Sidelinger, Rev. Sci. Instrum. 64, 2035 (1993).

${ }^{64}$ M. Chance, L. Miller, R. Fischetti, E. Scheuring, W. Huang, B. Sclavi, Y. Hai, and M. Sullivan, Biochemistry-Us 35, 9014 (1996).

${ }^{65}$ A. Arcovito, C. Ardiccioni, M. Cianci, P. D’Angelo, B. Vallone, and S. D. Longa, J. Phys. Chem. B 114, 13223 (2010)

${ }^{66}$ S. D. Longa, A. Arcovito, B. Vallone, A. Castellano, R. Kahn, J. Vicat, Y. Soldo, and J. Hazemann, J. Synchrotron Radiat. 6, 1138 (1999).

${ }^{67}$ S. D. Longa, A. Arcovito, M. Girasole, J. Hazemann, and M. Benfatto, Phys. Rev. Lett. 87, 155501 (2001).

${ }^{68}$ A. Arcovito, D. Lamb, G. U. Nienhaus, J. Hazemann, M. Benfatto, and S. D. Longa, Biophys. J. 88, 2954 (2005).

${ }^{69}$ S. D. Longa, A. Arcovito, M. Benfatto, A. Congiu-Castellano, M. Girasole, J. Hazemann, and A. L. Bosco, Biophys. J. 85, 549 (2003).

${ }^{70}$ M. Benfatto, S. D. Longa, and C. Natoli, J. Synchrotron Radiat. 10, 51 (2003).

${ }^{71}$ D. Robin, R. Alvis, A. Jackson, and R. Holtzapplet, Micro Bunches: A Workshop on the Production, Measurement and Applications of Short Bunches of Electrons and Positrons in Linacs and Storage Rings, Upton, L.I., New York, 1995.

${ }^{72}$ M. Abo-Bakr, J. Feikes, K. Holldack, P. Kuske, W. Peatman, U. Schade, G. Wustefeld, and H. Hubers, Phys. Rev. Lett. 90, 094801 (2003).

${ }^{73}$ X. Huang, J. Safranek, J. Corbett, Y. Nosochkov, J. Sebek, and A. Terebilo, Proceedings of the 2007 IEEE Particle Accelerator Conference (PAC 07). 25-29 Jun 2007, Albuquerque, New Mexico. 22nd IEEE Particle Accelerator Conference, p. 1308.

${ }^{74}$ R. W. Schoenlein, S. Chattopadhyay, H. H.W. Chong, T. E. Glover, P. A. Heimann, C. Shank, A. Zholents, and M. S. Zolotorev, Science 287, 2237 (2000). 